\title{
Dendritic Cell Responses and Function in Malaria
}

\section{OPEN ACCESS}

Edited by:

Noah Butler,

The University of lowa, United States

Reviewed by:

Silvia Beatriz Boscardin

University of São Paulo, Brazil

Michelle N. Wykes,

QIMR Berghofer Medical Research

Institute, Australia

Anton Goetz,

National Institutes of Health (NIH),

United States

${ }^{*}$ Correspondence:

Xi Zen Yap

zen.yap@radboudumc.n

Rachel J. Lundie

lundie.r@wehi.edu.au

tThese authors have contributed equally to this work

¥Present Address:

Xi Zen Yap,

Radboud University Medical Centre,

Nijmegen, Netherlands

Rachel J. Lundie,

The Walter and Eliza Hall Institute of

Medical Research, Parkville, VIC,

Australia

Specialty section:

This article was submitted to

Microbial Immunology,

a section of the journal

Frontiers in Immunology

Received: 30 October 2018

Accepted: 12 February 2019

Published: 04 March 2019

Citation:

Yap XZ, Lundie RJ, Beeson JG and

O'Keeffe M (2019) Dendritic Cell

Responses and Function in Malaria.

Front. Immunol. 10:357.

doi: 10.3389/fimmu.2019.00357

\begin{abstract}
Xi Zen Yap ${ }^{1,2 * \neq}$, Rachel J. Lundie ${ }^{1,3 * \neq \neq}$, James G. Beeson ${ }^{1,2,4}$ and Meredith O'Keeffe ${ }^{1,3}$
${ }^{1}$ Burnet Institute, Melbourne, VIC, Australia, ${ }^{2}$ Department of Medicine, Dentistry, and Health Sciences, The University of Melbourne, Parkville, VIC, Australia, ${ }^{3}$ Department of Biochemistry and Molecular Biology, Biomedicine Discovery Institute, Monash University, Clayton, VIC, Australia, ${ }^{4}$ Department of Microbiology and Central Clinical School, Monash University, Clayton, VIC, Australia
\end{abstract}

Malaria remains a serious threat to global health. Sustained malaria control and, eventually, eradication will only be achieved with a broadly effective malaria vaccine. Yet a fundamental lack of knowledge about how antimalarial immunity is acquired has hindered vaccine development efforts to date. Understanding how malaria-causing parasites modulate the host immune system, specifically dendritic cells (DCs), key initiators of adaptive and vaccine antigen-based immune responses, is vital for effective vaccine design. This review comprehensively summarizes how exposure to Plasmodium spp. impacts human DC function in vivo and in vitro. We have highlighted the heterogeneity of the data observed in these studies, compared and critiqued the models used to generate our current understanding of DC function in malaria, and examined the mechanisms by which Plasmodium spp. mediate these effects. This review highlights potential research directions which could lead to improved efficacy of existing vaccines, and outlines novel targets for next-generation vaccine strategies to target malaria.

Keywords: dendritic cells, malaria, Plasmodium falciparum, Plasmodium vivax, vaccines

\section{INTRODUCTION: MALARIA}

Malaria remains one of the greatest challenges to public health in the developing world. It is caused by infection with the Plasmodium species of Apicomplexans, which have a complex life cycle spanning multiple organ sites (Figure 1), facilitated by multiple morphologically and antigenically distinct life stages, and expression of multiple antigens (1-5).

The Plasmodium life cycle bridges two hosts: mosquitoes, where sexual replication occurs, and humans, where the parasite undergoes asexual replication. The latter begins when an infected mosquito injects sporozoite-stage parasites from mosquito salivary glands into the skin (Figure 1). A small fraction of sporozoites will travel to the liver, where the sporozoite will traverse hepatic tissue until it locates a suitable hepatocyte. The subsequent exoerythrocytic form will release merozoites into the bloodstream upon rupture (6). Plasmodium vivax can also enter a dormant liver stage known as the hypnozoite, which can mature and produce merozoites weeks to years after the initial infection $(7,8)$. Despite being only $1 \mu \mathrm{m}$ in size, the merozoite expresses a range of parasite proteins that ligate host red blood cell (RBC) ligands to drive invasion. After invasion the merozoite forms a parasitophorous vacuole in host cells, where it begins to mature into a trophozoite (9).

From 18 to $32 \mathrm{~h}$ post-invasion, the trophozoite increases DNA replication and metabolic activity. The mid-trophozoite stage exports various parasite proteins, including those crucial to host pathology, such as the $P$. falciparum erythrocyte membrane protein 1 (PfEMP1) (10). At $34 \mathrm{~h}$ post-invasion, the parasite becomes a 


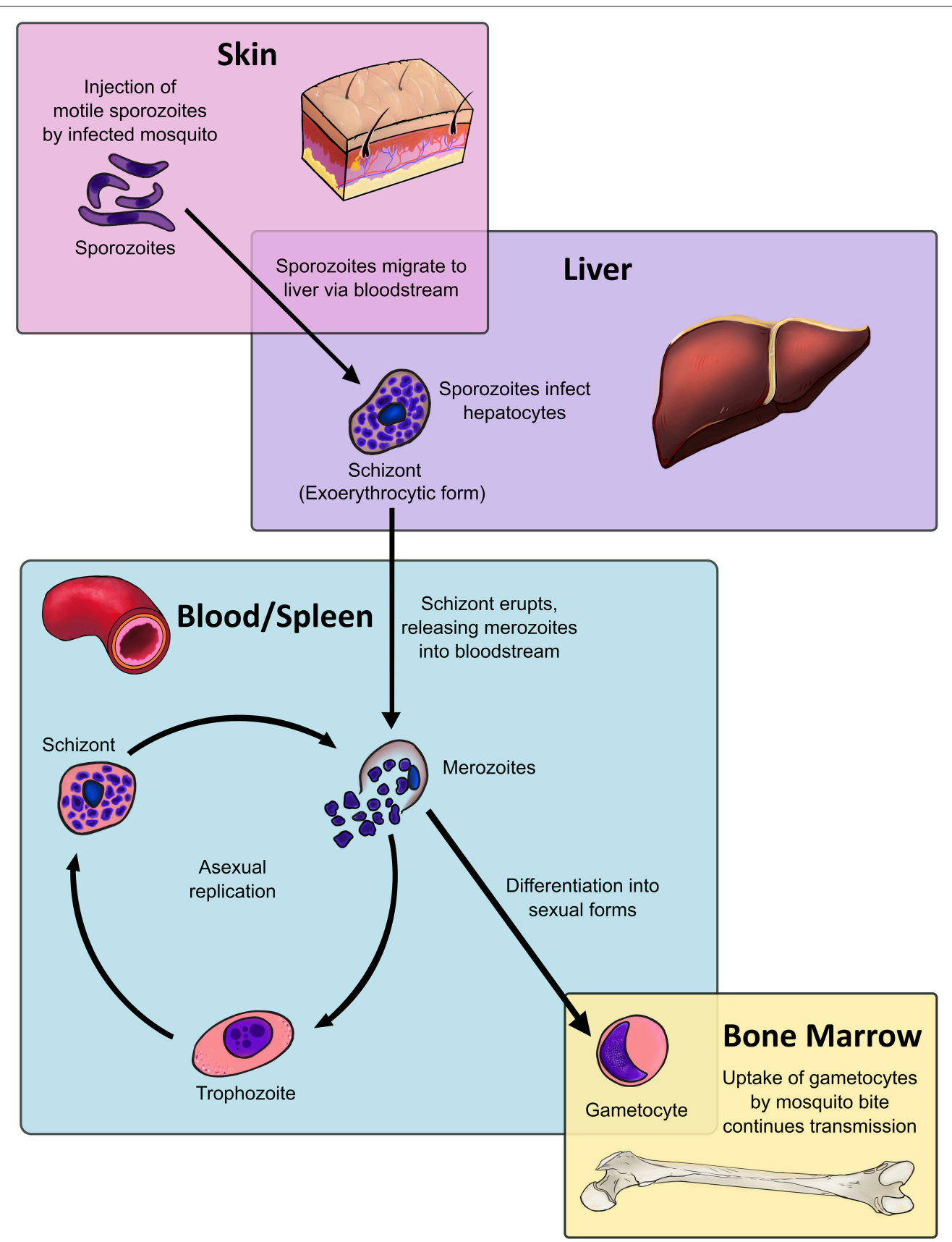

FIGURE 1 | Dendritic cells, located throughout the body at various stages of maturity, interact with all stages of the malaria parasite life cycle within the human host. The Plasmodium life cycle encompasses multiple life stages across a range of tissues. The asexual life cycle in the human host begins when mosquitoes inject sporozoites, the highly motile infectious life stage, into the host's skin. The sporozoite migrates to the liver, where it traverses multiple host cells before entering into an exoerythrocytic form. The exoerythrocytic form matures into a multinucleate schizont, which releases merozoites into the bloodstream upon lysis. Merozoites infect host red blood cells and mature into intraerythrocytic life stages known as trophozoites, which are highly metabolically active. After DNA replication the trophozoite will become a blood-stage schizont, which will lyse and release daughter merozoites into the bloodstream, resuming the process. Instead of becoming trophozoites, a fraction of merozoites will instead differentiate into sexual stages known as gametocytes, which sequester in the bone marrow. Only at the end of their maturation process do gametocytes re-enter the bloodstream, where they are taken up by mosquito bite to commence sexual replication in the mosquito host and continue the cycle.

multinucleate, segmented stage known as the schizont. After $48 \mathrm{~h}$ of intracellular maturation and replication, the schizont ruptures, destroying the erythrocyte and releasing parasite metabolites, waste products, and between 16 to 32 daughter merozoites are released into the bloodstream (9), where the cycle will begin afresh. 
After 7-15 days in circulation, a small proportion of $P$. falciparum trophozoites will commit to sexual replication, where the process of schizogony is replaced by the formation of sexual stages known as gametocytes $(11,12)$. Generation of $P$. vivax gametocytes is much faster, with gametocytes being detectable in circulation from 3 days post-infection $(13,14)$. Gametocytes undergo five maturation stages: stages I-IV preferentially sequester in the bone marrow (BM) and spleen (15-17) while stage $\mathrm{V}$ gametocytes re-enter the circulation, where they can be taken up by the bite of infected mosquitoes (18).

The effect of each malaria life stage on host immune function is not well understood, nor are the broader underlying mechanisms of antimalarial immunity. It is frequently observed that individuals living in highly endemic regions develop clinical immunity against symptomatic disease, but generally do not develop sterilizing immunity that completely protects against infection. Antibodies are a crucial component of naturally acquired clinical immunity, as passive transfer of immunoglobulins from malaria immune to non-immune individuals is sufficient to reduce parasitaemia and resolve symptoms (19). Furthermore, clinical immunity appears in most cases to be relatively short-lived and broadly declines in the absence of boosting [reviewed in (20)]. An improved understanding of antimalarial immunity will enable development of future vaccines which can accelerate acquisition of clinical immunity, or better yet, induce sterile immunity.

\section{Malaria Vaccines}

The most advanced malaria vaccine candidate to date is RTS,S, which targets the circumsporozoite protein (CSP) of $P$. falciparum. RTS,S has shown modest efficacy in Phase III clinical trials, with 29 and $36 \%$ efficacy in young infants and young children, respectively over 3-4 years, with a booster dose given at 20 months (21). The sub-optimal efficacy of RTS,S and its failure to elicit protective immunity in many recipients is poorly understood (21-23). To elucidate the immunological responses that future malaria vaccines should aim to induce or improve upon, it is vital to understand how different parasite life stages modulate the host immune system. This review focuses specifically on the interactions between malaria parasites and dendritic cells (DCs), sentinel antigen presenting cells of the immune system that are crucial for generating effective immune responses and immunological memory.

\section{Dendritic Cells}

DCs function as a crucial bridge between innate and adaptive immunity. In a healthy individual, DCs constitute only $1 \%$ of all peripheral blood mononuclear cells (PBMC) (24-26), yet they exert potent regulatory effects on both the innate and adaptive immune system (Figure 2). Upon encountering foreign antigens in the presence of pathogen associated molecular patterns (PAMPs), DCs undergo a process of maturation and migrate to the spleen and draining lymph nodes where they interact with pathogen-specific $\mathrm{T}$ cells. In addition to presenting antigen via major histocompatibility complex (MHC) surface molecules, DCs express co-stimulatory molecules required for naïve $\mathrm{T}$ cell proliferation and differentiation into effector cells, including CD40, CD80 (B7-1), and CD86 (B7-2). Through secretion of cytokines and chemokines, DCs recruit other immune cells and influence the nature of the adaptive $\mathrm{T}$ and $\mathrm{B}$ cell response, ultimately leading to clearance of infected cells and extracellular pathogens (Figure 2). Crucially, DCs are present at all clinically relevant sites for the development of Plasmodium life stages, namely the skin, blood, bone marrow, spleen, and liver (Figure 1).

Based on the expression of CD11c and CD123, human DCs can be broadly classified into plasmacytoid DCs (pDC; $\mathrm{Lin}^{-} \mathrm{HLA}_{-\mathrm{DR}}{ }^{+} \mathrm{CD} 11 \mathrm{c}^{-} \mathrm{CD}_{123^{+}}$) and conventional DCs (cDC; $\mathrm{Lin}^{-} \mathrm{HLA}-\mathrm{DR}^{+} \mathrm{CD} 11 \mathrm{c}^{+} \mathrm{CD}_{123^{-}}$) populations. The $\mathrm{pDC}$ are the body's major producers of the anti-viral interferon (IFN)- $\alpha$, though they constitute only $0.35 \%$ of PBMCs $(25,26)$. These cells are crucial in antiviral responses. The $\mathrm{cDCs}$ specialize in priming and presenting antigen to $\mathrm{T}$ cells (27), and constitute $0.6 \%$ of PBMCs $(25,26)$. Using the blood dendritic cell antigen (BDCA) markers, it is possible to further differentiate $\mathrm{CDC}$ populations into $\mathrm{cDC} 1\left(\mathrm{BDCA}-3^{+} / \mathrm{CD} 141^{+}\right)$and $\mathrm{cDC} 2\left(\mathrm{BDCA}^{-}{ }^{+} / \mathrm{CD} 1 \mathrm{c}^{+}\right)$ subsets, while pDCs express BDCA-2 (CD303) and BDCA-4 (CD304) (28-30).

Given the central role of DCs in sensing infection and orchestrating immune responses, it is not surprising that many pathogens have evolved immune evasion strategies which specifically target DCs in order to interfere with innate and adaptive immune responses (31-34). Thus, understanding how DCs initiate and maintain effective immune responses against malaria parasites, whilst minimizing detrimental and life-threatening immunopathology, is imperative for vaccine development.

\section{AT THE MEETING POINTS: SITES OF DC AND PLASMODIUM SPP. INTERACTION}

Interactions between DCs and Plasmodium parasites occur at every stage of the parasite life cycle within the human host: skin (35), liver (36), and most importantly within the blood and spleen (37), where the majority of host pathology occurs. Recent studies have also revealed that the bone marrow (BM) compartment is a major tissue reservoir for gametocyte development and proliferation of malaria parasites (38-41). Tissue-resident DCs in each of these sites have the potential to endocytose parasite components and initiate the development of specific adaptive immune responses to Plasmodium infection. Importantly, DCs in these tissues exist in different maturation states and thus vary in their ability to influence adaptive and innate immune responses and induce inflammatory responses. Within the liver, DCs are thought to induce tolerogenic responses to prevent induction of harmful immunopathology $(42,43)$, whilst in spleen, DCs propagate strong immune responses, and blood DCs have an intermediate phenotype with a lower capacity for inducing inflammation compared to their splenic counterparts (44). 
A Immature dendritic cell

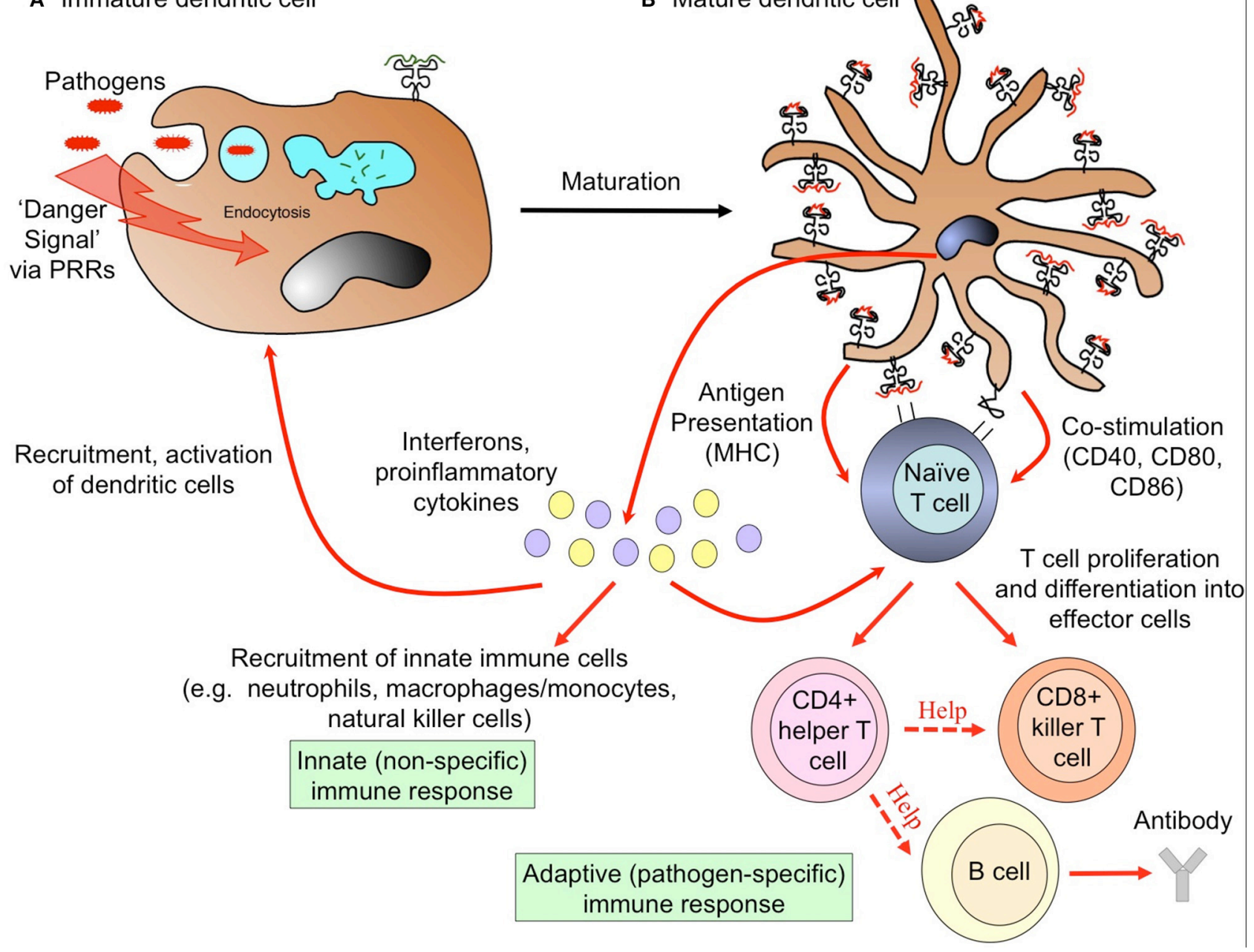

FIGURE 2 | Dendritic cells link innate and adaptive arms of the immune system. (A) Uptake of pathogens and recognition of pathogen-associated "danger signals" by pattern recognition receptors (PRRs) triggers dramatic morphological and functional changes in DCs, termed maturation. These changes involve the formation of dendrites, down-regulation of antigen uptake, and redistribution of major histocompatibility complex (MHC) molecules from intracellular endocytic compartments to the cell surface. (B) Mature DCs migrate to draining lymph nodes and present information about the invading pathogen in the form of processed peptides loaded onto MHC molecules to naïve T cells. Upregulation of $\mathrm{MHC}$ and co-stimulation molecules enables activated DCs to initiate adaptive $\mathrm{T}$ and $\mathrm{B}$ cell immune responses, the nature of which are determined by the cytokine milieu. This initiates the cascade to an adaptive immune response, leading to clearance of infected cells, and extracellular pathogens. Activated mature DCs also secrete interferons and proinflammatory cytokines that recruit circulating innate immune cells to provide rapid defense against infection.

\section{Skin and Liver DC Interactions With Sporozoites: Lessons From Murine Models}

The skin is the site of first contact between DCs and Plasmodium spp. Studies in mice have demonstrated that sporozoites remain in the skin for up to $60 \mathrm{~min}$ prior to entering the circulation, after which they lose motility (45). Remarkably, up to $50 \%$ of sporozoites become trapped in the dermis, while $30 \%$ of those that succeed in entering the circulation enter lymphatic rather than blood vessels (45). Thus, the majority of sporozoites fail to reach the bloodstream and are instead phagocytosed by DCs in the skin-draining lymph nodes, which prime protective $\mathrm{CD} 4^{+}$ (46-48) and $\mathrm{CD}^{+} \mathrm{T}$ cell responses $(49,50)$. It is likely that a substantial proportion of immunity to sporozoite stages arises predominantly in response to these "failed" sporozoites.

Interestingly, there is some evidence that sporozoites which arrest within the liver may promote induction of limited liver-stage immunity. A murine study demonstrated that apoptosing hepatocytes infected by irradiated sporozoites triggered recruitment of circulating blood DCs to the liver (51). These DCs phagocytosed apoptotic hepatocytes and migrated to lymph nodes, where they induced protective IFN- $\gamma$-producing $\mathrm{CD}^{+} \mathrm{T}$ cell responses (50).

Importantly, in the above study, infiltrating DCs from the cutaneous lymph nodes initiated immune responses, not 
liver-resident DCs (50). In humans (52) and mice (53), tissueresident liver DCs are reportedly less mature than blood DCs, as they are poor at antigen processing and express only low levels of costimulatory markers. While liver DCs in humans are capable of inducing allogeneic $\mathrm{T}$ cell responses, they are less effective at this than their blood counterparts, and therefore promote a $\mathrm{T}$ cell phenotype that is less responsive to subsequent stimulation $(52,54)$. When considered in conjunction with their high capacity for IL-10 secretion (52), the liver DC phenotype may be one that promotes a more tolerogenic environment, favorable to sporozoite survival. This could partly explain why sterile immunity rarely occurs in response to natural infection, with tolerogenic liver-resident DCs acting to suppress inflammatory responses which would induce protection. Studies using mouse models with humanized livers have shown promise for investigating Plasmodium spp. skin-to-liver transfer $(55,56)$. In combination with FMS-like tyrosine kinase 3 ligand (Flt3-L)treated cord blood engrafted humanized mice, which produce large quantities of human DCs similar to those seen in blood (57), combined liver-immune system humanized mice could be a useful avenue to investigate DC involvement in liverstage immunity.

\section{The Bone Marrow As a Reservoir for Gametocytes}

A similar phenomenon of immune tolerance may occur in the BM, which emerging evidence suggests is a privileged developmental niche for the transmission stages of Plasmodium. Autopsy studies have indicated that both $P$. vivax and $P$. falciparum $(15,58-61)$ gametocytes sequester in the BM, the latter of which is supported by the presence of a PfEMP1 type capable of binding BM endothelium (62). Poor immune responses to parasites in this milieu may be due to tolerogenic potential of the BM microenvironment. There is very little data on BM DCs. One non-human primate study indicated that $\mathrm{BM}$-derived $\mathrm{CD} 123^{+} \mathrm{HLA}^{-\mathrm{DR}^{+}} \mathrm{pDC}$ had a decreased capacity to express co-stimulatory molecules in response to pathogens relative to blood DCs (63), while $\mathrm{CD}_{11 \mathrm{c}^{+}} \mathrm{BM}$ cells in a murine study had a similar capacity for $\mathrm{T}$ cell stimulation relative to their blood and spleen counterparts (64). However, it is not clear whether the $\mathrm{CD} 11 \mathrm{c}^{+}$population in the latter study was comprised solely of DCs.

No studies to date have examined how DCs in the BM respond to sequestered parasites, although one murine study has reported that pDCs, present in the BM at frequencies 20 times higher than in the blood or spleen, are the major producers of IFN- $\alpha$ during P. yoelii 17X YM infection (65). If the BM is indeed a reservoir for infection, as is suggested by recent primate studies (41), studying whether BM DCs are capable of initiating antimalarial immune responses will be important for achieving elimination.

\section{Blood and Spleen DC Interactions With Malaria Blood-Stages}

Blood-stage parasitaemia provides multiple opportunities for blood and splenic DCs to interact with parasites. The parasite spends the majority of the asexual blood-stage cycle within the host RBC. While P. vivax exclusively infects reticulocytes, which express surface MHC and can therefore be cleared by $\mathrm{CD}^{+} \mathrm{T}$ cells (66), P. falciparum also infects mature RBCs, which do not express surface MHC molecules, thus enabling host immune evasion. Despite this, the blood-stage is an antigenically rich phase of the Plasmodium life cycle [reviewed in (67, 68)], affecting a large proportion of host cells and triggering potent inflammatory immune responses that cause most of the symptoms of malaria. Maturation of parasitized RBCs (pRBCs) culminates in lysis of the host $\mathrm{RBC}$, releasing merozoites into the circulation. Merozoites that fail to invade a new $\mathrm{RBC}$ will remain in the circulation where they are directly phagocytosed (69) or circulate to the spleen for clearance. The PfEMP1 molecule, which is expressed on the pRBC surface, may play a dual role in this life stage. While it is a prime target for antibodies in naturally acquired immunity (70), one report suggests it may also modulate immune function via binding to CD36 on APCs, including DCs (71). Furthermore, PfEMP1-mediated sequestration in the periphery is long held to be a parasite adaptation aimed at avoiding splenic clearance (72).

DCs play a vital role in initiating and regulating adaptive immunity to blood-stage malaria (73-75). However, there is strong evidence that Plasmodium parasites modulate DC maturation and function to interfere with the development of protective immune responses. Data from mouse models indicate that blood-stage infection suppresses both existing and developing liver-stage immunity by inhibiting DC activation (76), and inhibits DCs from responding to subsequently encountered pathogens (77-79). Importantly, murine studies suggest that DCs also play a role in the induction of immunemediated pathology, including the life-threatening syndrome of cerebral malaria $(80,81)$. Thus, it is of vital importance that we understand the factors governing the ability of DCs to alter the balance between protection and pathology.

\section{DCs, Malaria, and Unanswered Questions}

The majority of DC-Plasmodium interactions in humans have been studied in two ways: (1) studying peripheral blood DCs from currently or previously infected individuals, or (2) measuring DC responses to parasite stimuli in vitro. In the first method, DCs were isolated from the blood of individuals who were naturally or experimentally infected with malaria. The surface phenotype and function of these DCs was compared to uninfected controls, either the same individuals prior to or postinfection, or a matched control group (82-102). In the second method, DCs from malaria-naïve individuals were stimulated with Plasmodium products to assess the resulting phenotype. The majority of reports which used the latter generated DCs from monocytes in vitro using GM-CSF and IL-4 (71, 103-106), while a minority reported responses from bona fide DCs from blood $(83,85,107,108)$.

As such, there is limited knowledge about how naïve DC subsets resident in different human tissues and blood respond to Plasmodium, and what factors influence this response. This knowledge is vitally important for designing vaccine strategies which specifically enhance the ability of DCs to induce protective responses while limiting induction 
of immunopathology. Understanding how naïve DC function is altered by Plasmodium exposure will provide insight into how DCs are affected in infected individuals, and therefore what vaccine strategies will be required to overcome this altered phenotype.

\section{PERIPHERAL BLOOD DC RESPONSES TO NATURAL OR EXPERIMENTAL PLASMODIUM INFECTION}

A total of 24 ex vivo studies to date have examined how natural or experimental exposure to Plasmodium spp. affects the activation phenotype and function of human peripheral blood DCs, in both acute infection and after prior exposure (summarized in Table 1). The following sections analyse these studies in detail, according to species infection.

\section{Phenotypes and Responses During $P$. falciparum Infection}

Plasmodium falciparum is responsible for a high burden of morbidity and mortality in pregnant women and children, and can cause severe and fatal disease outcomes including cerebral malaria, miscarriage, and multiple organ failure (110). Infected persons typically present to hospital when blood-stage infection becomes symptomatic, which can occur nine to 30 days after the initial infection (111). Classifying malaria cases as mild/uncomplicated vs. severe is based on specific clinical features, including but not limited to coma, haemoglobinuria, vital organ dysfunction, or respiratory distress (110). The majority of ex vivo studies have been carried out in settings of high P. falciparum transmission, focusing on the phenotype and function of DCs in high-risk groups including children and pregnant women (Table 1).

\section{DCs and $P$. Falciparum in Children in High-Transmission Settings}

In a DC study comparing infected children to non-infected controls in a holoendemic setting, Kenyan children hospitalized with mild vs. severe malaria exhibited decreased HLA-DR expression on DCs and reduced DC numbers in circulating blood, regardless of disease severity (82). A subsequent study which followed children during malaria and after treatment showed that malaria specifically decreased HLA-DR expression on $\mathrm{cDC}$ but not $\mathrm{pDC}$ subsets, and reduced the ability of DCs to induce allogeneic $\mathrm{T}$ cell proliferation in mixed leucocyte reactions (MLR) (96). Furthermore, infection correlated to an increase in absolute numbers of circulating BDCA-3 $3^{+}$ cDC1s. Importantly, these effects of $P$. falciparum on DC phenotype and function were still observed 14 days after hospital discharge and curative treatment (96), suggesting that malariainduced immunosuppression can persist for some time after parasite clearance.

A subsequent study was conducted in Mali, another holoendemic setting, where DC function was compared between infected and non-infected children from the Fulani and Dogon ethnic groups. DCs from children aged 2-10 years displayed reduced HLA-DR expression after malaria exposure (100). Infection was also associated with increased proportions of circulating $\mathrm{BDCA}-2^{+} \mathrm{pDC}$ and $\mathrm{BDCA}-3^{+} \mathrm{cDC} 1$ populations, with reduced CD86 expression in the former (100). In this study genetic differences were proposed to play a role in clinical outcomes of P. falciparum infection due to differences in cytokine production between the 2 ethnic groups, with PBMCs from Dogon children displaying significantly impaired cytokine production, correlating with more severe fever and higher parasitaemia (100). These responses could be attributed in part to reduced DC function, including a reduction of pDC-derived IFN- $\alpha$ production in response to TLR9 ligands.

More recently, Guermonprez et al. reported that children with malaria, regardless of disease severity, had an increased frequency of the BDCA-3 ${ }^{+} \mathrm{CDC1}$ population (102). This correlated with increased serum concentrations of the DC growth factor Flt3-L that preferentially increases $\mathrm{pDC}$ and $\mathrm{CDC} 1$ in vivo $(112,113)$. During malaria, Flt3-L is produced by mast cells in response to uric acid metabolism by Plasmodium parasites (102).

Together, these studies suggest that malaria in children in high-transmission settings negatively impacts DC activation marker expression and modulates DC function. The low activation status of peripheral DCs may be due to sequestration of activated DCs in affected tissues. Moreover, an increased number of circulating BDCA- $3^{+} \mathrm{cDC} 1 \mathrm{~s}$ appears to be a common feature of malaria in this setting. Urban et al. also showed that DC dysfunction persisted after the resolution of malaria (96), leaving these individuals vulnerable to co-infections. The apparent contradiction between reduced DC numbers in the first study (82) and elevated numbers of BDCA-3 ${ }^{+}$cDC1s in the second study (96) is likely due to more sophisticated gating strategies in the latter, enabling discrimination of individual DC subsets (96), rather than classifying all HLA-DR ${ }^{+}$cells as DCs (82). Rigorous and well-defined flow cytometry gating strategies that use an appropriate combination of antibodies to DC subsetspecific surface markers are imperative for DC research and may help to resolve some of the apparent discrepancies in the literature.

\section{DCs and $P$. Falciparum in Pregnancy in High-Transmission Settings}

Four studies evaluating changes in DC populations in infection during pregnancy have yielded conflicting results. Two studies, one from Gabon (94) and one from Benin and Tanzania (101), observed that overall DC numbers were decreased in pregnant women infected with $P$. falciparum compared to uninfected matched pregnant controls, while a study from Senegal (97) reported a decrease in the $\mathrm{pDC}$ population only relative to nonpregnant uninfected controls. Another study from Benin (109) did not observe any difference in DC numbers between infected and non-infected pregnant women. Changes in surface activation marker expression varied across studies (Table 1).

Again, different gating strategies may underlie some of the differences observed between these studies. Simply gating on $\mathrm{CD} 123^{+}$or $\mathrm{CD} 11 \mathrm{c}^{+}$populations may run a risk of false positives if isolation and lineage staining is not extensive enough. Use of cord blood $(94,97)$ or placenta-derived (97) DCs may also 


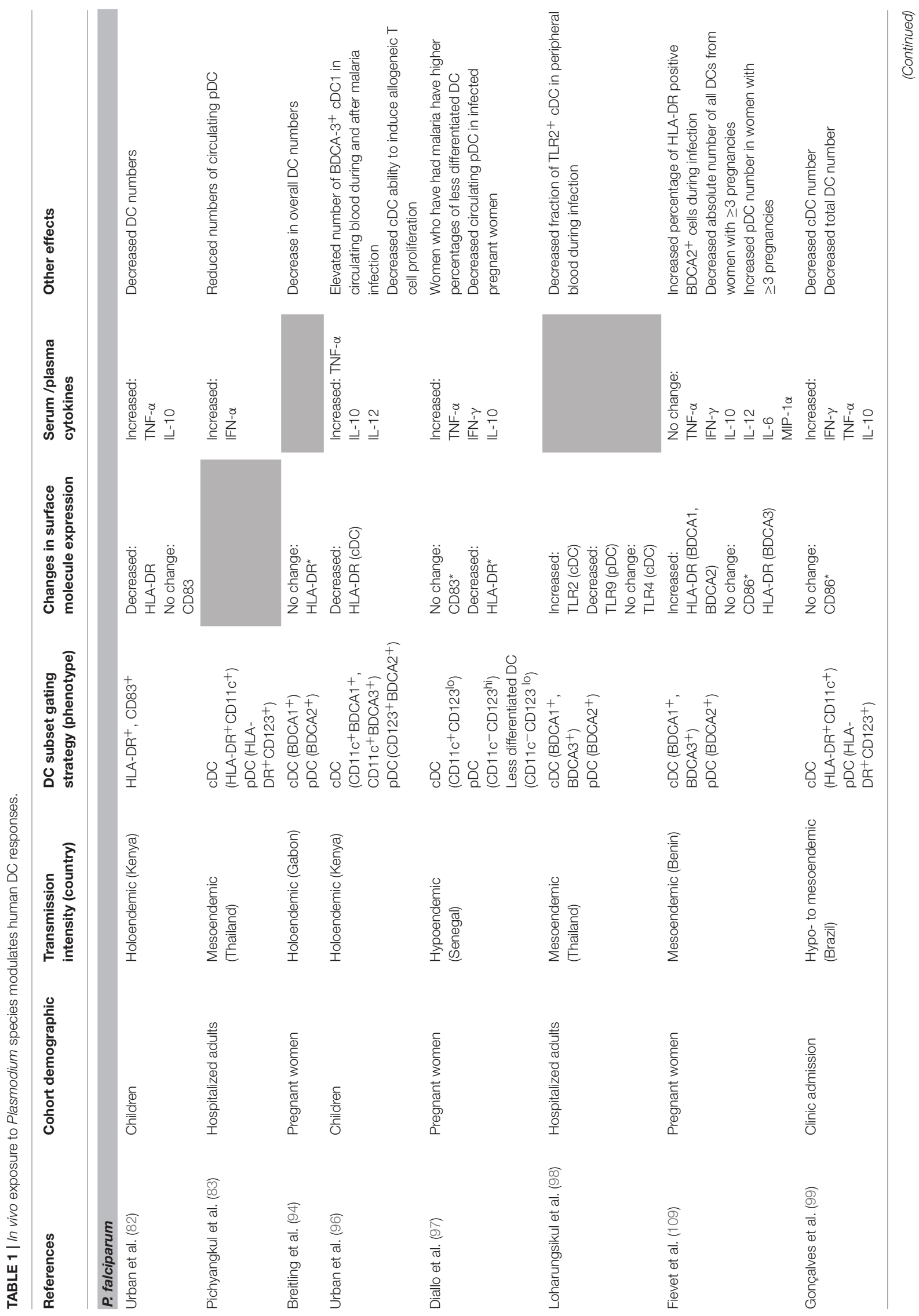




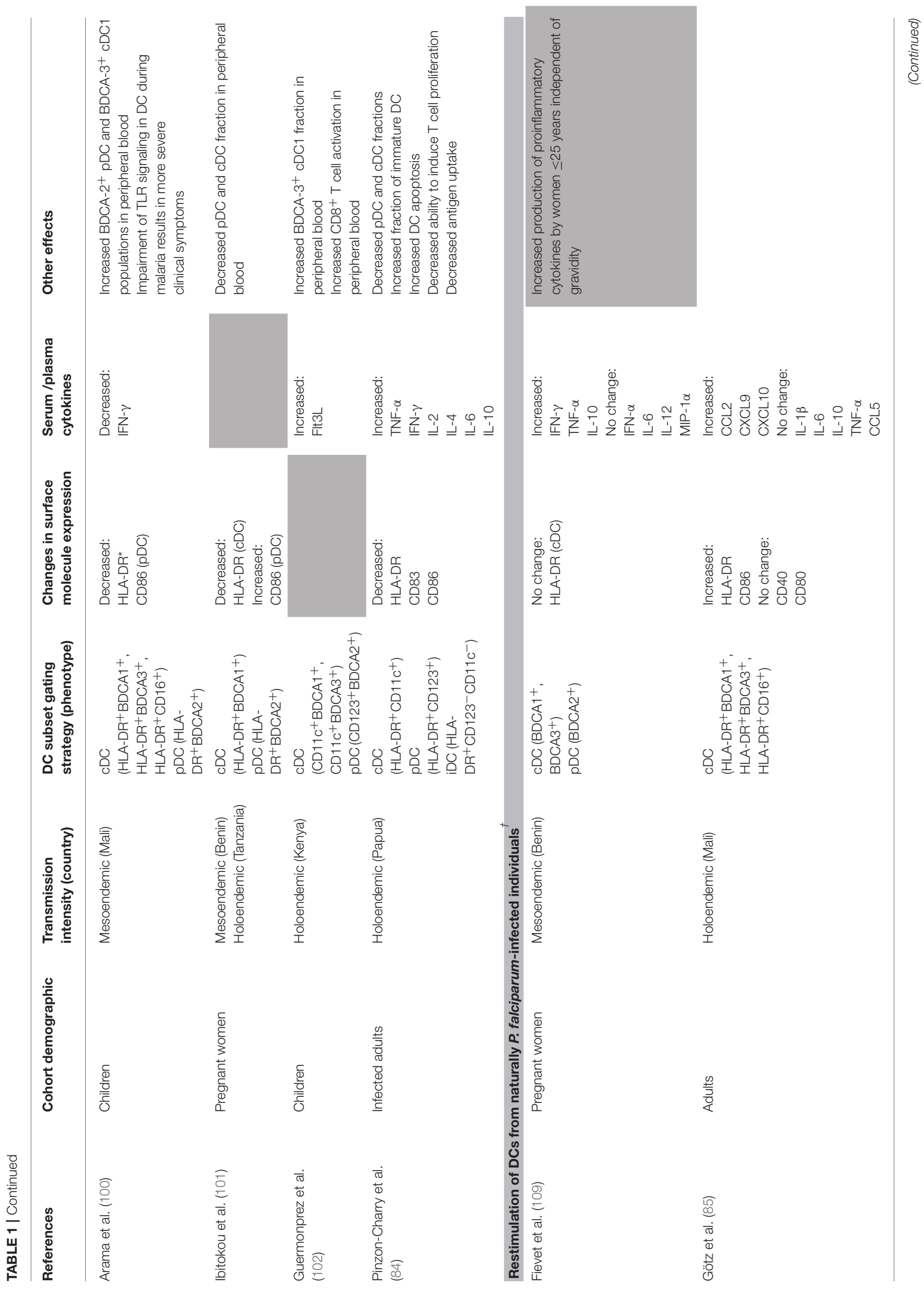




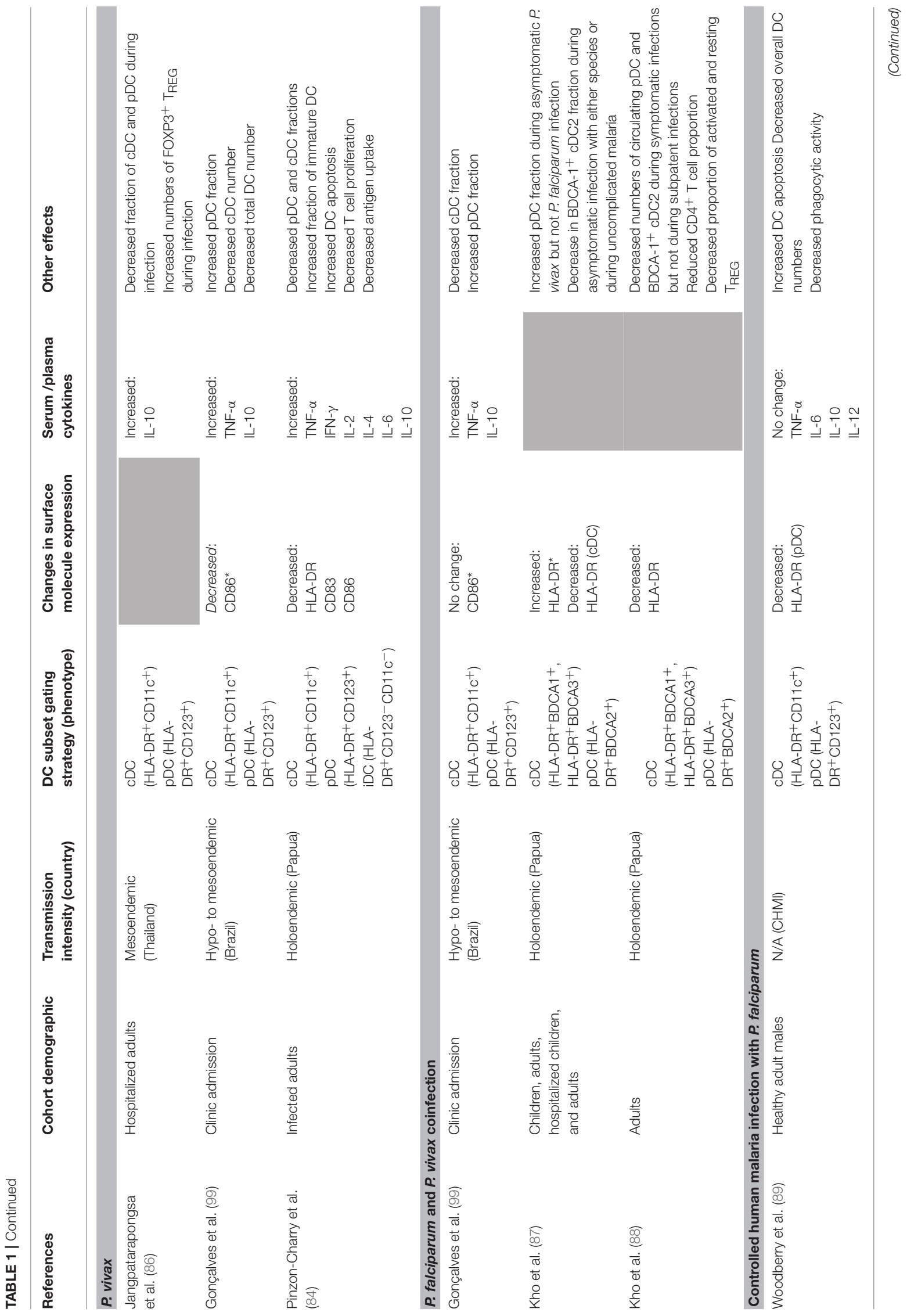




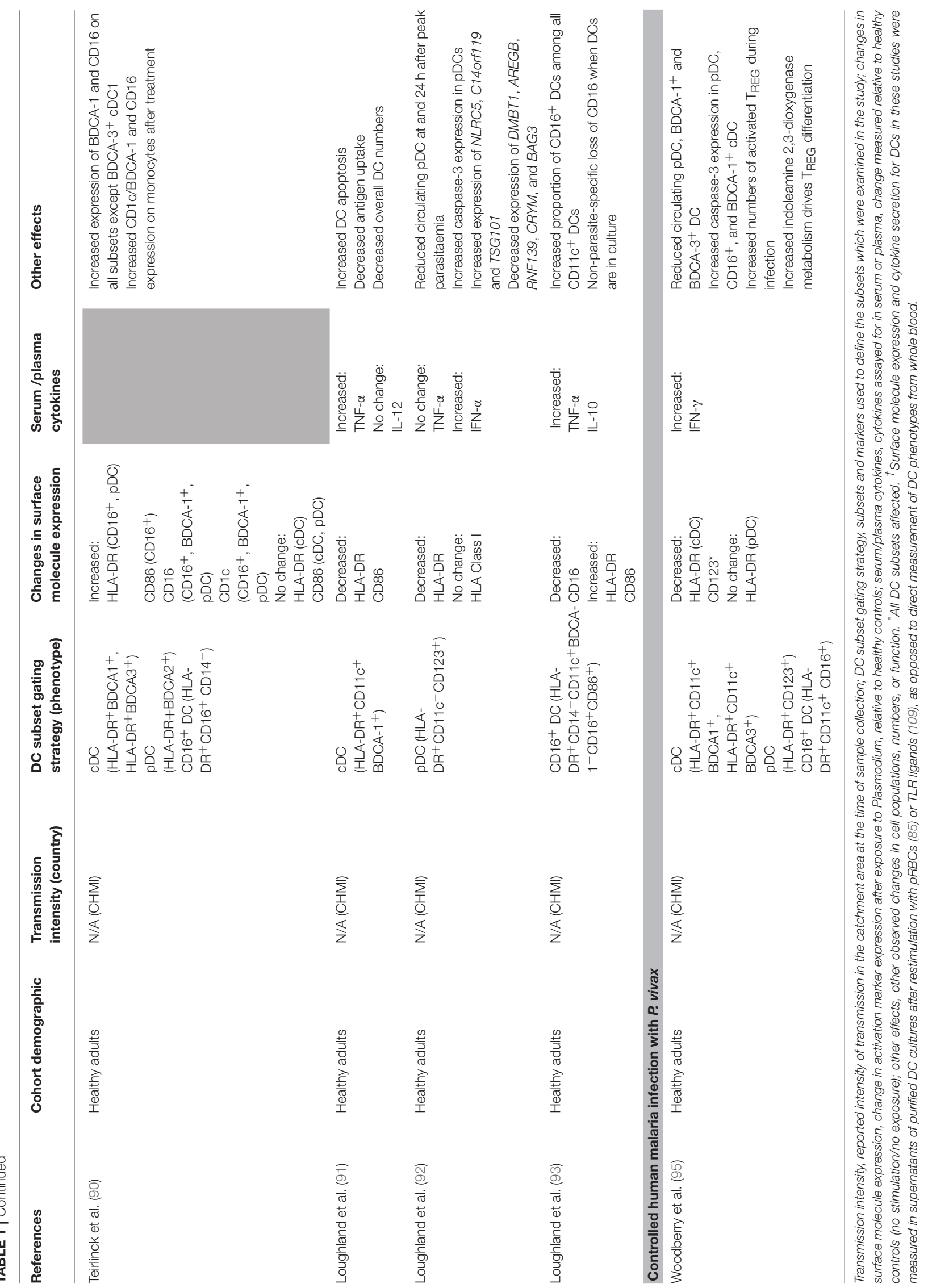


contribute to phenotypic differences between these DCs and peripheral blood DCs, due to the unique microenvironments of these pregnancy-associated tissues. Gravidity can also be an important contributing factor. Since primigravid women are at the highest risk of severe inflammatory disease [reviewed in (114)], the proportion of women in their first pregnancy should always be accounted for in immunological studies. Inclusion of pregnant non-infected controls is also imperative to determine whether pregnancy itself is a confounding factor affecting DC function during malaria.

\section{Function of DCs From Naturally Exposed Individuals}

Three studies of adults with symptomatic malaria carried out in Thailand (98), Brazil (99), and Papua (84) provide insights into how P. falciparum immunity develops in lowertransmission settings. Within the Thailand cohort, activation marker expression was not assessed, but circulating numbers of pDCs were significantly reduced in both mild and severe malaria compared to healthy controls. IFN- $\alpha$ levels in the serum increased (83), but it was not established whether this directly correlated with $\mathrm{pDC}$ function. The percentage of immature $\mathrm{HLA}-\mathrm{DR}{ }^{+} \mathrm{CD} 11 \mathrm{c}^{-} \mathrm{CD} 123^{-}$cells in circulation increased, while the fractions of circulating $\mathrm{CD} 11 \mathrm{c}^{+} \mathrm{cDCs}$ and $\mathrm{CD}_{12} 3^{+}$pDCs were decreased. DCs from infected participants were apoptotic (upregulated the apoptotic marker Annexin-V) and were defective at antigen uptake and induction of naïve $\mathrm{T}$ cell proliferation in allogeneic T cell activation assays (84). All three cohorts were recruited via clinical admissions, which self-selects for individuals with lower pre-existing immunity and perhaps a more naïve phenotype.

In short, it appears that while impairment is more pronounced in high-transmission settings due to frequent re-infection and higher overall parasite burden, downregulation of DC function is a common feature of malaria. Considering that malaria induces potent inflammation, this DC phenotype may therefore be comparable to what is seen in other inflammatory diseases such as bacterial sepsis (115), HIV (116), or HCV (117). In these patients it is also common to observe reductions in circulating DC numbers $(115,116)$ and reduced HLA-DR $(117)$ or CD86 $(115,117)$ expression. Persistent systemic inflammation may therefore explain this reduction in DC function in naturally malaria-infected persons. Again, more rigorous classification of $\mathrm{cDC} 1, \mathrm{cDC} 2$, and pDCs may clarify some of the discrepancies amongst different reports.

\section{Stimulation of DCs From Naturally Exposed Individuals}

In a study examining DC responses to TLR stimulation after natural $P$. falciparum infection, DCs from naturally exposed pregnant women in Benin were collected from cord blood (109). Whole PBMC cultures were stimulated with TLR4 ligand LPS, TLR3 ligand polyinosinic:polycytidylic acid (polyI:C), or TLR9 ligand $\mathrm{CpG}-\mathrm{A}$ ODN to stimulate BDCA- $1^{+} \mathrm{cDC} 2, \mathrm{BDCA}-3^{+}$ cDC1, or pDCs, respectively, due to the high expression of each TLR on these specific DC subsets (118). Synthetic hemozoin prepared from haemin chloride was also used for DC stimulation. There was no difference in HLA-DR expression between infected and non-infected women upon stimulation with either TLR ligands or hemozoin. PBMCs from infected women produced more TNF- $\alpha$ and IL-10 in response to CpG-A stimulation, more IFN- $\gamma$ in response to polyI:C, and more TNF- $\alpha$ in response to hemozoin relative to non-infected women (109).

Only one study to date has stimulated DCs from naturally exposed individuals using pRBCs (85). DCs were purified from the blood of adults from a highly endemic region in Mali at the end of the transmission season and DC activation was compared to that in naïve controls. All exposed individuals were PCRnegative for infection at the time of enrolment (85). When stimulated with pRBCs at a ratio of $3 \mathrm{pRBCs}$ per DC, DCs from these individuals upregulated expression of HLA-DR and CD86 and expressed CCL2, CXCL9, and CXCL10, but did not produce any IL-1 $\beta$, IL-6, IL-10, or TNF- $\alpha$ (85). In Section 4 , this review outlines how a lack of cytokine secretion is commonly observed in in vitro studies of bona fide DC, and therefore should not necessarily be considered a sign of DC suppression. However, it is interesting that when DCs isolated from malaria-exposed individuals were stimulated with $\mathrm{pRBCs}$ following cessation of high malaria transmission (85), DCs could express an activatory surface phenotype in response to stimulation. Thus, it may be that sustained reductions in transmission allow restoration of DC function.

\section{TLR Modulation in DCs by P. falciparum}

Only one study to date has investigated the ability of $P$. falciparum to modulate TLR expression on DCs as a potential mechanism of immune suppression (98). In this study, individuals with severe or mild $P$. falciparum infection exhibited increased TLR2 expression on cDCs but decreased TLR9 expression on pDCs, with no observable change in TLR4 expression (98) compared to healthy controls. The severity of infection did not impact these changes in TLR expression. Moreover, the fraction of TLR2 ${ }^{+}$DCs in the periphery decreased during infection (98). TLR2, TLR4, and TLR9 have all been implicated in sensing of Plasmodiumderived "danger signals." Namely, TLR2 and TLR4 recognize glycophospholipid (GPI) anchors for merozoite surface proteins (119), and TLR9 detects Plasmodium DNA (120). As this is the only study to assess TLR expression profiles during Plasmodium infection, it is unclear whether this effect is a common feature of malaria. Nevertheless, it suggests that even low-level Plasmodium infections can modulate host responses by downregulating the signals required for APC activation.

\section{The Effects of Natural $P$. vivax Infection on DC Phenotype and Function}

Plasmodium vivax is the second major malaria pathogen. It inhabits a broader geographical range than P. falciparum, posing a risk to more than 3.2 billion individuals worldwide (121). Its pathogenic potential is enhanced by its ability to become a latent hypnozoite in the liver (7), but as it exclusively infects reticulocytes (122), it is difficult to maintain in culture and remains relatively understudied. Immunity to $P$. vivax has primarily been studied in symptomatic persons who present to healthcare. As the geographical ranges of $P$. vivax and $P$. falciparum transmission overlap, it is often difficult to exclude 
the immunological impact of prior $P$. falciparum exposure. Nonetheless, it is possible to describe the acute effects of $P$. vivax single-species infection, even though an individual's infection history may be unclear, if diagnosis is sufficiently rigorous. The gold standard for species-specific diagnosis is PCR. However, in resource-poor settings rapid diagnostic tests are typically used.

Due to the paucity of studies from $P$. vivax-exposed individuals it is difficult to conclude the effects of $P$. vivax malaria on DC function. DC numbers decreased during infection, both as a fraction $(84,86)$ and as total numbers (99). In the latter study, the $\mathrm{pDC}$ fraction was increased while $\mathrm{cDC}$ numbers decreased (99). Another study observed a decrease in both pDC and cDC fractions, as well as increased DC apoptosis (84). Plasmodium vivax malaria has also been reported to down-regulate CD86 expression on DCs $(84,99)$.

\section{The Effect of Mixed Plasmodium Infections on DC Function}

Phenotypic analyses of peripheral blood DC from individuals coinfected with two Plasmodium spp. support similar reductions in overall DC numbers as seen in individuals experiencing single infections $(87,88,99)$. However, it is not yet known whether this correlates to impairments in DC function. A study from Gonçalves et al. in a mesoendemic area of Brazil found that asymptomatic individuals infected with both P. falciparum and $P$. vivax had decreased circulating $\mathrm{cDCs}$ but increased circulating pDCs (99). Studies in a holoendemic region of Papua found that pDC fractions increased during asymptomatic $P$. vivax but not $P$. falciparum infection, with $\mathrm{pDC}$ and $\mathrm{BDCA}-1^{+} \mathrm{cDC} 2$ fractions decreasing during acute infection with either species $(87,88)$. No changes were observed in the $\mathrm{BDCA}-3^{+} \mathrm{cDC} 1$ fraction in children or adults during acute or asymptomatic infection with either species $(87,88)$, in contrast to the findings in African cohorts $(96,100,102)$. HLA-DR expression on DCs was increased during asymptomatic $P$. vivax infection (87), but decreased during acute mixed or single-species infections $(87,88)$.

It is interesting that HLA-DR expression on DCs was positively correlated with parasitaemia in children with asymptomatic $P$. vivax infection, but negatively correlated with parasitaemia in adults with asymptomatic $P$. falciparum infection (87). Thus, it may be that the two major pathogenic Plasmodium species polarize the immune system in different ways. This data also suggests fundamental differences in how childrens' and adults' DCs respond to Plasmodium exposure-an important factor to keep in mind considering the at-risk populations for either species.

\section{Insights From Controlled Malaria Infection Models Controlled Human Malaria Infection With P. falciparum}

The development of a controlled human malaria infection model (CHMI) has produced valuable insights into antimalarial immunity. In one CHMI model which has been used to study DC in malaria, healthy volunteers who are typically malaria-naïve were inoculated with an ultra-low $(<180)$ or low $(1,800)$ dose of $P$. falciparum pRBCs thawed from a pre-prepared biobank. Atovaquone/proguanil or artemether/lumefantrine treatment was administered 6 days post-infection (ultra-low-dose group) or when parasitaemia reached 1,000 parasites per mL (lowdose group). Despite the low parasite biomass of the inoculum in the low-dose group, an estimated 20 times lower than the number of merozoites released from an infected hepatocyte after sporozoite replication (123), DC numbers were significantly decreased in the low-dose group due to increased DC apoptosis (89). Intriguingly, infection-induced apoptosis appeared to be exclusive to HLA-DR ${ }^{+}$cells, including DCs. Furthermore, the decrease in DC numbers coincided with the peak of symptomatic malaria, and while $\mathrm{cDC}$ numbers recovered to pre-infection levels after drug treatment, pDC numbers remained at $47 \%$ of baseline $60 \mathrm{~h}$ post-cure (89). HLA-DR expression on pDCs was also impaired. Importantly, DCs from the low-dose group displayed impaired phagocytosis, which persisted for $36 \mathrm{~h}$ after drug cure. In contrast, the ultra-low-dose group experienced no symptoms and no DC impairment (89). This study suggests that a certain parasite biomass is required for functional impairment of DCs. However, since the ultra-low-dose group were treated prior to development of symptoms, it is unclear whether an ultra-low dose is sufficient to induce immunity that can control sub-symptomatic parasitaemia, or whether immune impairment would have eventuated if parasitaemia had been allowed to develop.

\section{Function of $p D C$ s and BDCA-1 ${ }^{+}$cDC2s during CHMI}

A second controlled infection study from Loughland et al. utilized a similar low- (1800 pRBCs) and ultra-low (150 pRBCs) dose to more closely study BDCA-1 ${ }^{+}$cDC2 activation (91) and pDC function (92) after controlled infection. Unlike the prior study, patients were treated upon reaching a parasitaemia of 1000 pRBCs per $\mathrm{mL}$, regardless of initial parasite inoculum. Importantly, both groups experienced a decrease in HLA-DR expression on $\mathrm{BDCA}^{+}{ }^{+} \mathrm{cDC} 2 \mathrm{~s}$ that coincided with peak parasitaemia but also persisted $24 \mathrm{~h}$ after drug treatment (91). However, only the highdose group exhibited decreased DC numbers, increased DC apoptosis, and reduced phagocytic capacity relative to baseline $(91,92)$. A positive association was also observed between phagocytic activity and HLA-DR expression at peak parasitaemia (91).

The ability of DCs to respond to TLR stimulation after exposure to malaria was also evaluated in these studies (91) by restimulating DCs taken from participants during peak parasitaemia. Interestingly, the $\mathrm{BDCA}-1^{+} \mathrm{cDC} 2$ from individuals in the high-dose group were impaired in their capacity to upregulate HLA-DR and CD86 in response to stimulation with TLR1/2, TLR4, and TLR7 ligands or whole pRBCs. This impairment was DC-specific, as monocytes' capacity for activation marker expression was unaltered by malaria exposure (91). In contrast, pDCs restimulated with TLR7 and TLR9 ligands upregulated expression of HLA-DR, CD123, and IFN$\alpha$, and upregulated CD86 in response to TLR7 stimulation (92). The cDC1 subset was not examined in these studies. These results were similar to TLR stimulations of cord blood 
DCs from pregnant women, where CpG-A stimulation of pDCs showed enhancement of cytokine production in infected individuals (109), though caution must be taken when comparing naïve CHMI participants to naturally-exposed pregnant women in Benin.

Together, these studies suggest that a single infection is sufficient to impair $\mathrm{cDC}$ function, while $\mathrm{pDC}$ function is more resilient. As discussed further on, this highlights a need to further study pDC function during malaria and the potential role of this subset in immunopathology.

\section{$\mathrm{CD}^{+}{ }^{+}$DC function in CHMI}

The $\mathrm{CD} 6^{+}$DC subset's status as a steady-state DC rather than a monocyte subset that acquires DC-like characteristics during inflammation remains unclear $(27,124,125)$. Improved strategies for distinguishing "true" $\mathrm{CD} 16^{+} \mathrm{DCs}$ from $\mathrm{CD} 16^{+} \mathrm{CD} 14^{-}$ monocytes have not yet been established, although a recent single-cell RNAseq study highlighted a population of BDCA$1^{-} \mathrm{BDCA}-3^{-} \mathrm{CD} 16^{+} \mathrm{cDCs}$ that is transcriptomically distinct from monocytes (126). However, two studies have examined the role of $\mathrm{CD}_{16}{ }^{+}$"DCs" in malaria, both in CHMI. Both studies observed that relative to pre-CHMI levels HLA-DR and CD86 expression in these DCs increased after curative treatment $(90,93)$ and $24 \mathrm{~h}$ prior to peak parasitaemia (93). At peak parasitaemia $\mathrm{CD} 16^{+} \mathrm{DCs}$ had an increased ability to spontaneously produce TNF- $\alpha$, IL-10, and IL-12. CD16 ${ }^{+}$DCs collected at peak parasitaemia and restimulated with pRBCs expressed higher levels of IL-10 relative to baseline (93). When restimulated with TLR1/2 or TLR4 ligands, these $\mathrm{CD}_{1}{ }^{+} \mathrm{DCs}$ produced high levels of TNF- $\alpha$ and moderate amounts of IL-10 and IL-12. When restimulated with TLR7 ligands, the $\mathrm{CD}^{+} 6^{+}$DCs produced TNF- $\alpha$ only (93). While caution must be taken in ascribing bona fide DC status to the $\mathrm{CD} 16^{+}$ DCs, these studies indicate that these cells are activated during infection and in the highly inflammatory environment posttreatment. Their high production of both TNF- $\alpha$ and IL-10, which may aid in killing or suppression of DCs, respectively, suggest that they could be major contributors to DC modulation, including that seen many days post-treatment and clearance of infection (96).

\section{CHMI With $P$. vivax}

Due to the technical difficulty of maintaining $P$. vivax in continuous culture, to date only one CHMI has been published using $P$. vivax (95). In this study, peripheral DC numbers were significantly reduced during acute infection relative to baseline, though this was concurrent with an overall reduction in circulating PBMC (95). All subsets (BDCA-3 ${ }^{+} \mathrm{cDC} 1 \mathrm{~s}, \mathrm{BDCA}-$ $1^{+} \mathrm{cDC} 2 \mathrm{~s}, \mathrm{pDCs}$, and $\left.\mathrm{CD}^{+} 6^{+} \mathrm{cDCs}\right)$ upregulated caspase3 during acute infection and after treatment, suggesting that the reductions in DC numbers in the periphery could also be due to increased apoptosis. Overall, DC impairment by $P$. vivax CHMI was largely similar to what was observed with P. falciparum $(89,91)$; HLA-DR expression on BDCA$1^{+} \mathrm{cDC}$ was reduced during acute infection and $24 \mathrm{~h}$ after treatment (95).

\section{Ex vivo DCs in Plasmodium Infection: What Do We Know?}

In summary, Plasmodium infection can result in reduced DC numbers in the periphery, both as an absolute number $(89,91$, $94,99)$ and as a proportion of total leucocytes $(82,97,101)$, reportedly due to increased DC apoptosis $(84,89,91)$. DC capacity for phagocytosing antigen is also decreased $(89,91)$, which correlates with DC activation (127), yet their ability to induce $\mathrm{T}$ cell proliferation in allogeneic $\mathrm{T}$ cell stimulation assays is impaired $(84,89,96)$. HLA-DR expression is generally decreased $(87-89,91,92,95-97,100,101)$, with some variability between DC subsets (Table 1). It is not clear whether the reduction in HLA-DR is due to an increase in new immature DCs in the circulation, or direct downregulation by parasites. There is little consensus regarding other markers: reports on CD83 $(84,97)$ and CD86 expression are contradictory, though CD86 tends to be elevated on pDCs and decreased on DCs as a total population $(83,84,91,100,101)$.

It is also unclear whether the decrease in the number of circulating DCs is due to cell death, as suggested by the upregulation of caspase-3 $(89,91,95)$ or annexin V $(84)$, or due to increased migration to lymphoid tissues. Decreased DC numbers in both natural and experimental infection, however, coincided with increased serum levels of IL-10 $(82,84,86,96,97,99)$ and TNF- $\alpha(82,84,91,96,97,99)$, indicating a potential cytokinemediated mechanism of DC loss. One subset in particular defied this trend: proportions of $\mathrm{BDCA}-3^{+} \mathrm{cDC} 1 \mathrm{~s}$ were increased during $P$. falciparum infection $(96,100,102)$, and remained elevated for some time after acute infection (96). The BDCA-3 ${ }^{+}$ cDC1 subset is associated with the initiation of $\mathrm{CD}^{+}$killer $\mathrm{T}$ cell responses and the secretion of IL-12 (128). It is likely that increases in serum Flt3-L lead to increased numbers of these DC in the periphery during infection, but these circulating DC do not appear to be capable of inducing functional responses. Further complicating the matter, the BDCA- $3^{+} \mathrm{cDC} 1$ subset is not elevated in single or mixed infections from Papua, where transmission intensity is comparable $(87,88)$.

Overall, the different methods and markers that have been used to study DCs in this variety of settings makes it difficult to clearly define universal parameters of DC loss of function. It is possible that the DC downregulation described in these studies is a feedback loop promoting regulatory mechanisms in the face of severe malaria-induced inflammation, and that DC downregulation in malaria is not necessarily detrimental to host survival. However, the presence of functional DCs is required for effective vaccine responses, and it is still not clear how malaria-induced DC downregulation affects survival to other pathogens. There is an overall need to understand how these DC phenotypes correlate to clinical outcomes, or at minimum, how malaria directly affects DC function. It will be important to clarify whether DC downregulation during natural infection translates to suppression, namely loss of generalized immune function against non-malaria pathogens or inflammatory stimuli.

In light of this, in vitro studies of DC function are vital for three purposes: (1) clarifying the phenotype of DC suppression, (2) determining precisely how malaria modulates DC function, 
and (3) identifying whether this is through direct interaction with DCs or indirectly through soluble mediators, including cytokines such as TNF- $\alpha$.

\section{DEFINING THE INTERACTIONS BETWEEN DCS AND PLASMODIUM SPP. IN VITRO}

To date, relatively few studies have investigated direct interactions between Plasmodium spp. and human DCs in vitro. The majority of these studies have examined the responses of human monocyte-derived DCs (moDCs), since they can be easily generated in large numbers from $\mathrm{CD} 14^{+}$PBMCs or BM monocytes by co-culture with GM-CSF \pm IL-4 $(129,130)$. MoDC are themselves heterogeneous and contain cells with a cDC-like phenotype with high expression of MHC class I and II, BDCA-1, CD40, CD80, and CD11c (129), and macrophage-like cells (131). Transcriptomic analysis indicates that moDC are highly distinct from blood $\mathrm{CD}_{16}{ }^{+}, \mathrm{cDC} 2\left(\mathrm{BDCA}^{-}{ }^{+}\right)$, and $\mathrm{cDC1}\left(\mathrm{BDCA}-3^{+}\right) \mathrm{cDC}$ subsets and therefore do not accurately represent the diversity of DC populations or their functions in vivo (124). Other recent findings indicate that monocyte-derived inflammatory DCs in humans are more similar to macrophages than to bona fide DCs [reviewed in $(27,125)]$. Thus, moDCs may not be a representative model for investigating bona fide human DC responses. These caveats must be considered when interpreting the data from in vitro studies (summarized in Table 2).

\section{MoDCs and Intracellular $P$. falciparum Blood-Stage Parasites}

Initially, $P$. falciparum pRBCs were thought to suppress moDC function in vitro (103) as, when co-cultured with moDCs at a concentration of 100 parasites per DC, they impaired moDC activation via contact-dependent CD36-mediated mechanisms (103). In this study, DCs co-incubated with CD36-binding parasite lines displayed decreased expression of co-stimulatory markers CD40, CD54/ICAM-1, CD80, CD83, and CD86 in response to LPS stimulation, and had a low capacity for inducing allogeneic T cell proliferation (103). Co-incubation with nonCD36 binding parasite lines did not induce the same inhibition. However, a subsequent study found that a high ratio of pRBCs to DCs (100:1) inhibited LPS-induced DC maturation, cytokine production, and allogeneic $\mathrm{T}$ cell stimulation regardless of whether the parasite strain had a CD36-binding phenotype, and low doses of parasite (10:1) induced modest DC maturation and autologous $\mathrm{T}$ cell proliferation (104). This inhibition of LPS-induced DC maturation with high doses of pRBCs was co-incident with high levels of DC death in vitro (104).

Another study reported that a ratio of 10 pRBCs per moDC did not trigger upregulation of HLA-DR, CD83, or CCR7 on moDCs (132), contradicting the findings of Elliott et al. (104). However, the 100:1 ratio induced secretion of IL-1 $\beta$, IL-6, IL10 , TNF- $\alpha$, and upregulation of the pro-migratory chemokine receptor CXCR4 (132). Another report indicated that even at a ratio of 25 pRBCs per moDC, moDCs upregulated HLA-DR, CD40, CD80, and CD83 and secreted significantly higher levels of TNF- $\alpha$, IL-6, and IL-10 (105). At higher pRBC-to-DC ratios, there was a corresponding increase in DC death (105).

Addition of CD40L to pRBC-stimulated moDCs enhanced HLA-DR and CD80 expression while CD86 expression was greatly reduced relative to CD40L alone (105). Secretion of TNF$\alpha$, IL-12, and IL- 6 was also enhanced, while IL-10 secretion was unchanged relative to CD40L alone (105). In another study, exposure to schizont lysate triggered moDCs to upregulate CD86 but not CD80 or HLA-DR (106). These lysate-stimulated moDCs were capable of inducing allogeneic $\mathrm{T}$ cell differentiation into $\mathrm{T}_{\mathrm{H}} 1$ and regulatory $\mathrm{T}$ cells $\left(\mathrm{T}_{\mathrm{REG}}\right)$, both of which secreted high levels of IFN- $\gamma$. $\mathrm{T}_{\mathrm{REG}}$ induced in this fashion also secreted high levels of IL-10 and TGF $\beta$. Pre-incubating moDCs with parasite lysate did not affect their ability to undergo LPSdriven maturation (106). Lastly, moDCs stimulated with whole schizonts did not upregulate HLA-DR, CD80, or CD86, nor did they express cytokines or chemokines (Table 2) (85).

One explanation proposed by Elliott et al. (104) for the conflicting literature on the effect of pRBCs on moDC activation is that high ratios of $\mathrm{pRBCs}$ suppress DC function, while low ratios activate DCs (104), though in a recent study moDCs were not activated by stimulation with 3 pRBCs per DC (85). Alternately, variations in methodology are likely to contribute to some of the differences observed: different parasite strains and co-culture periods were used across all studies (Table 2). Moreover, the heterogeneity of moDC preparations can vary widely amongst different laboratories. Schizont lysate is also not a proxy for $\mathrm{pRBCs}$ as the lytic process produces a mixture of parasite membrane proteins, metabolites, and merozoites (107). The matter is further complicated by the multiple ways of defining "inhibition": whether pRBCs truly block DC activation in response to an external stimulus, and which stimuli in particular are susceptible to this manner of inhibition. Alternatively, it must be clarified whether pRBCs induce higher levels of DC death.

In summary, while a dose-dependent relationship between $\mathrm{pRBC}$ dose and moDC inhibition is suggested, this relationship must be substantiated by further studies examining the individual roles that different parasite stimuli, strains, and methodological factors have on the final DC phenotype, preferably focusing on bona fide DCs in future studies. A more rigorous definition of moDCs and how "activation" and "inhibition" are defined in these cells, particularly given how different groups have used different activatory cytokine stimulation methods to drive DC-like cells to begin with, will be imperative to resolve existing conflicts.

\section{Monocyte-Derived DCs and Other Plasmodium Life Stages}

Human DC responses to other Plasmodium life stages have been poorly investigated. Only one study has investigated moDC responses to $P$. falciparum merozoites (105). In this study, co-incubation with merozoites resulted in moDC secretion of TNF- $\alpha$, IL-16, and large amounts of IL-10, despite no changes in costimulatory marker expression (105). Co-incubating merozoites with moDCs in the presence of 


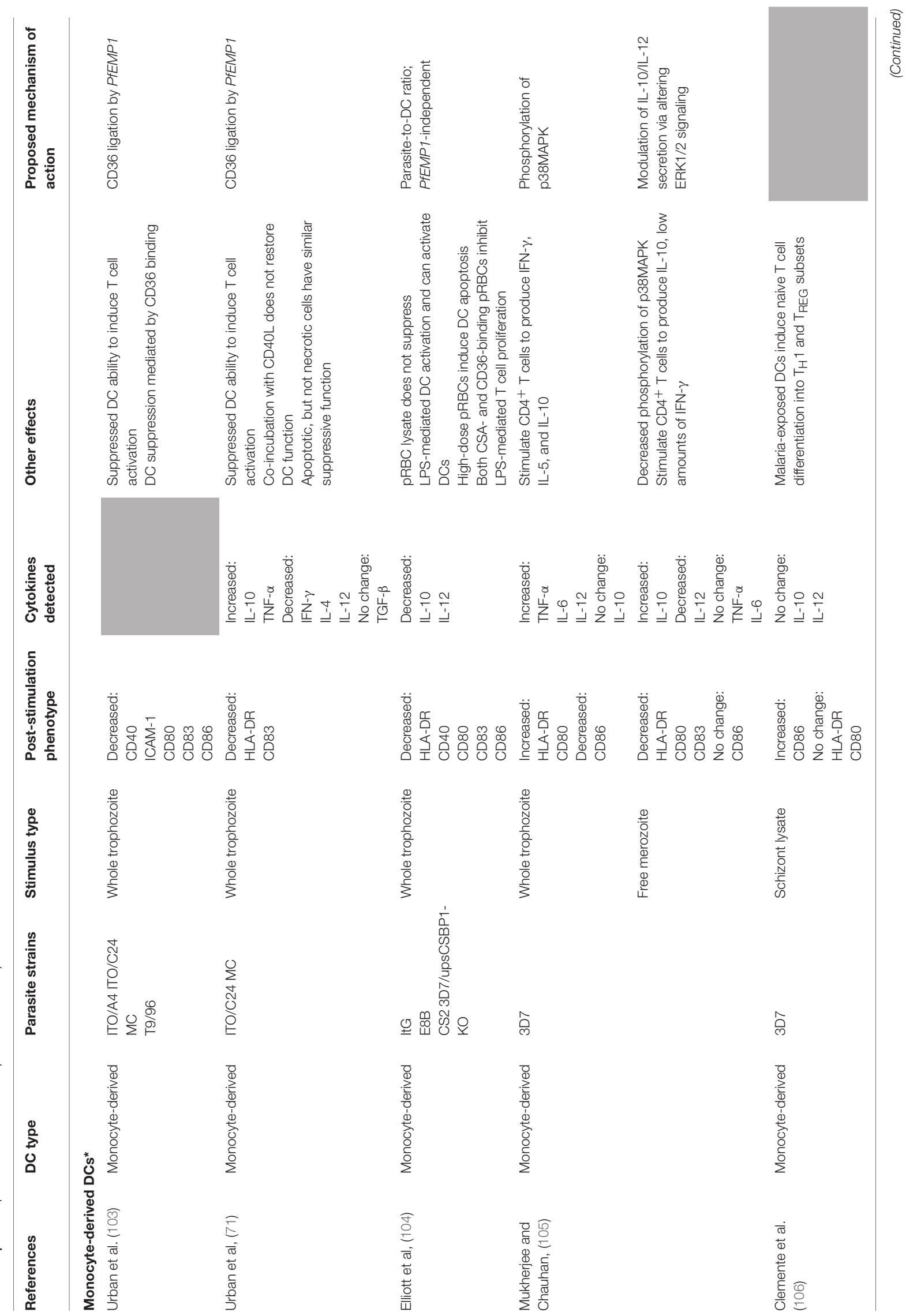




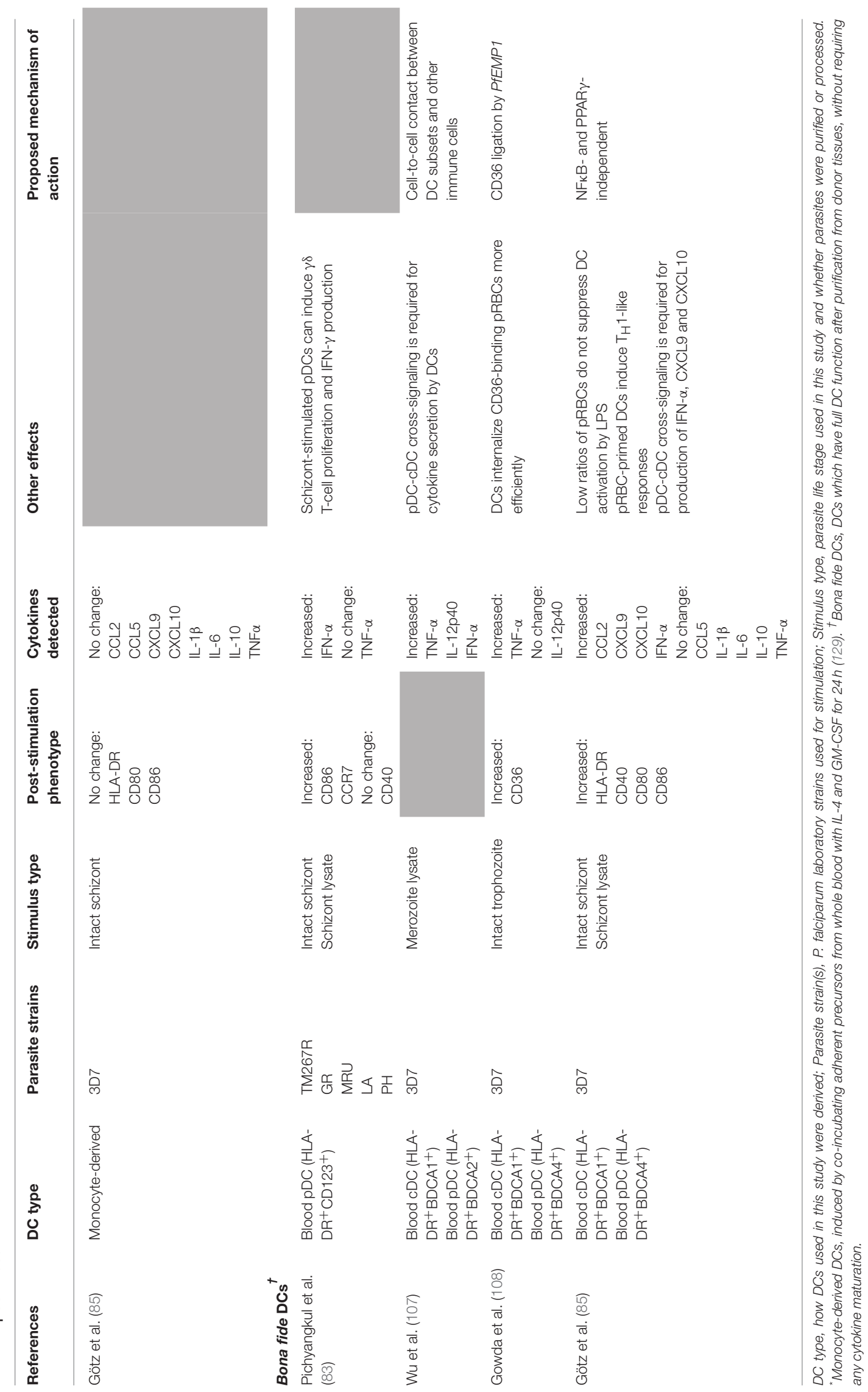


CD40L induced high CD86 expression but no increase in other costimulatory surface markers (105). CD40L also induced merozoite-stimulated moDCs to produce high levels of IL10 (105).

Likewise, only a single study to date has assessed moDC responses to $P$. vivax sporozoites (36). Prior to co-culture, moDCs were matured with TNF- $\alpha$ and LPS and primed, or not, with sporozoite extract. Primed moDC were more efficient than their unprimed counterparts at eliciting IFN- $\gamma$ secretion and autologous $\mathrm{T}$ cell proliferation in DC-T cell co-cultures, and $\mathrm{CD}^{+} \mathrm{T}$ cells stimulated by primed moDCs had greater cytotoxic effector activity against infected HC04 hepatocyte lines (36). It is not yet known how DCs respond to other liverstage parasites such as hypnozoites, exo-erythrocytic forms, or sexual-stage gametocytes.

\section{Interactions Between Bona fide Human DCs and $P$. falciparum}

Due to the technical challenges in obtaining large numbers of viable bona fide human DCs from peripheral blood, relatively few studies have investigated direct interactions between ex vivo blood DCs from healthy donors and P. falciparum merozoites or pRBCs (Table 2). To date, studies have focused on BDCA-1 ${ }^{+}$ $\mathrm{CDC} 2$ and $\mathrm{pDC}$ populations. None have examined the BDCA-3 ${ }^{+}$ cDC1 subset, likely owing to the rarity of this population. Both merozoites and $\mathrm{pRBCs}$ have been shown to induce blood DCs to upregulate CD40, CD80, and CD86 $(83,85)$, and to secrete IFN- $\alpha$ $(83,85,107)$, indicating that $P$. falciparum is capable of activating naïve DCs. Merozoites also triggered production of IL-12p40 and TNF- $\alpha$ (107). Additionally, a ratio of 3 pRBCs per DC resulted in upregulation of HLA-DR and increased expression of the chemokines CCL2, CXCL9, and CXCL10 (IP-10) (85), but did not trigger production of IL-1 $\beta$, IL- 6 , IL-10, or TNF- $\alpha$. Contrary to findings in moDCs, pRBCs did not suppress cytokine responses to LPS in bona fide DC, although this may be attributable to the lower pRBC-to-DC ratio used in this study (85). While the authors did not assess whether high doses of pRBCs modulated the ability of bona fide DCs to prime naïve T cells, as was shown for moDCs, bona fide DCs exposed to low doses of pRBCs were fully functional in their antigen presenting ability, inducing naive $\mathrm{T}$ cell proliferation and polarization toward an IFN- $\gamma$-producing $\mathrm{T}_{\mathrm{H}} 1$ phenotype (85). This does suggest, congruent with moDC studies $(104,106)$ and some CHMI studies $(89,91)$, that single, low-parasitaemia blood-stage infections of $10 \mathrm{pRBCs}$ per DC or fewer, equivalent to $200 \mathrm{pRBCs} / \mu \mathrm{L}$, may induce beneficial DC activation.

It is likely that cross-talk between different DC subsets plays an important role in immune responses to $P$. falciparum. Two studies that have examined this process indicate that DC crosstalk is required for production of TNF- $\alpha$, IL-12p40 (107), IFN- $\alpha$, CXCL9, and CXCL10 (also known as IP-10) (85) in response to pRBCs. In the context of antimalarial responses, DC activation appears to be contact-mediated and independent of IFN- $\alpha$, although partially mediated by the TLR9 pathway $(85,107)$, expressed by just the pDC subset of human DCs. While cDCs alone are sufficient for inducing $\mathrm{T}$ cell activation to pRBCs, the presence of pDCs affects the ability of activated $\mathrm{T}$ cells to proliferate and produce cytokines (85). When a mixed culture of $\mathrm{pDC}$ and $\mathrm{cDC}$ was used in $\mathrm{pRBC}$-primed autologous $\mathrm{T}$ cell stimulations, $\mathrm{T}$ cells trended toward reduced proliferation and production of IL-10, TNF- $\alpha$, IFN- $\gamma$, and IL-5, but increased IL2 secretion (85). It is possible that since the overall number of DCs for $\mathrm{T}$ cell stimulations was kept constant, reduced $\mathrm{T}$ cell activation was a consequence of the reduced proportion of $\mathrm{cDCs}$.

These data highlight a need for future studies to investigate not only the individual roles of bona fide DC subsets in immunity to malaria, but also to consider the complexity of the immune response and the influence of cell-to-cell interactions. This should be reflected in the establishment of better in vitro models and cell-based systems that more realistically mimic the dynamic interactions and cell behaviors that occur over the course of an immune response in vivo.

\section{Interactions With Parasite by-Products}

The cycle of parasite reproduction is fuelled by a range of host nutrients, not least of which is intraerythrocytic hemoglobin. Hemoglobin breakdown causes accumulation of toxic heme, which the parasite neutralizes by aggregating heme crystals into hemozoin (133). Hemozoin has been proposed to have both suppressive and activatory effects on DCs.

Initial studies reported that purified hemozoin induced CD1a, CD80, and CD83 upregulation and IL-12 secretion from moDCs, whereas monomeric heme and synthetic hemozoin ( $\beta$-hematin) did not (134). However, these results were contradicted by a subsequent study demonstrating impaired upregulation of HLADR, CD40, CD80, CD83, ICAM-1, and CD1a in moDCs preincubated with $P$. falciparum hemozoin (135). These conflicting results may be due to the use of different hemozoin sources. Depending on the method of purification, parasite hemozoin can be contaminated with parasite proteins, nucleic acids, and other by-products that can activate alternate pathways. It is possible for even purified hemozoin to adhere to environmental contaminants after purification (133). The altered activity of hemozoin on treatment with phospholipase D (135) and DNAse (136) indicate that contamination with nucleic acids or other parasite metabolites is a likely explanation for the observed variations, particularly since hemozoin has been shown to be a carrier for Plasmodium DNA (136).

Murine models have been vital in establishing how hemozoinmalaria DNA complexes activate DCs. Murine Flt3-ligandinduced DCs (137) stimulated with hemozoin chelated to $P$. falciparum DNA secreted high levels of RANTES, IL-12, and TNF- $\alpha$. In this system, hemozoin assisted in trafficking parasite DNA to intracellular endosomes, and activated DCs via a TLR9and MyD88-dependent signaling pathway (136). Hemozoin in isolation bound strongly to the murine TLR9 ectodomain while $\beta$-hematin, a synthetic form of hemozoin, was unable to activate DCs in this study (136). A subsequent study in humans did observe CD80, CD83, and CXCR4 upregulation on human moDCs after $\beta$-hematin stimulation (132), but the $\beta$ hematin-induced DCs were unable to induce allogeneic T cell proliferation (132). 
Uric acid, another toxic product of $P$. falciparum metabolism, has also been found to upregulate expression of CD80, CD86, and CD11c and to downregulate HLA-DR on purified human blood DCs (138). Uric acid also reportedly stimulated mast cells to produce high levels of the DC growth factor Flt3$\mathrm{L}$ in mice (102). Interestingly, DNAse treatment of uric acid abrogated its activatory effects on DCs (138), similar to what is seen with hemozoin. While uric acid is known to drive inflammation during Plasmodium infection through activation of the inflammasome [reviewed in (139)], the role of the inflammasome in anti-malaria DC responses and activation has not been investigated.

Together these studies highlight an important role for $P$. falciparum DNA as an activatory ligand, particularly in activating pDCs and driving production of IFN- $\alpha$ (107). Since only the pDC subset in humans expresses TLR9 [reviewed in (140)], ligation of TLR9 by $P$. falciparum DNA and subsequent cytokine production by pDCs may be one of the primary mechanisms by which human DCs are activated by Plasmodium $(107,136)$. Cytoplasmic pattern recognition receptors for Plasmodium DNA, which are expressed in all DC subsets, may also play a prominent role in anti-Plasmodium interferon responses (141, 142). Of particular interest are the role of STING-dependent responses in DCs and their role in anti-malaria responses. Considering the wide distribution of Plasmodium DNA throughout the host during infection (143), the human DC response to malarial DNA ex vivo and in vitro is one of the key gaps in knowledge that remains unaddressed.

Murine studies have identified a number of other immunostimulatory Plasmodium products, but their role in DC activation has not yet been investigated. Glycosylphosphatidylinositol (GPI) molecules, membrane anchors for Plasmodium surface proteins, are known ligands for TLR2 (144), expressed on human cDCs (118). Parasite RNA is known to induce type I IFN via TLR7/MyD88-dependent signaling (145), and TLR7 is highly expressed on human pDCs (118), the major producers of type I IFN. Finally, microvesicles are small organelles of $1 \mu \mathrm{m}$ of less in size, derived by blebbing of the plasma membrane, which are generated in high volumes during Plasmodium infection $(146,147)$. They can contain a range of parasite material, and are able to induce cytokine secretion from murine (148) and human (149) macrophages. In summary, considering the wide range of immunostimulatory molecules produced by Plasmodium spp., it remains interesting that the DC response to malaria is not always activatory. While further studies should continue to identify Plasmodium ligands that drive DC activation, this must be studied in combination with the factors that underlie DC suppression in malaria.

\section{DCS AND PLASMODIUM: OUTSTANDING QUESTIONS AND FUTURE DIRECTIONS}

Immunity to Plasmodium is complex, and many aspects of cellular immunity remain poorly understood, particularly the impact of malaria on DC function. A better understanding of DC responses to Plasmodium will provide insight into the low efficacy and relative short duration of protection of the current malaria vaccine RTS,S, as well as the slow acquisition of natural immunity in malaria-exposed individuals. One of the most important unresolved questions is one of DC "suppression": namely, whether exposure to Plasmodium spp., particularly $P$. falciparum, inhibits the ability of DCs to initiate and orchestrate effective immune responses. Determining precisely how DCs are modulated by $P$. falciparum is crucial for understanding the development of immunity to malaria.

Some of the most interesting insights into the effects of malaria-induced DC impairment come from field studies that stratified patients by severity of infection. Studies that analyzed mild vs. severe malaria cases separately did not observe significant differences in DC phenotype between the groups $(82,102)$, suggesting that there may be a "tipping point" beyond which DC dysfunction is altered regardless of the severity of clinical presentation. This is underscored by the similarities in DC phenotype between natural exposure and CHMI. The latter are a naïve population, but during acute infection and for at least $24 \mathrm{~h}$ after treatment they exhibited similar DC phenotypes to those seen in naturally infected cohorts. Repeated infections could lead to sustained downregulation of DC function. Considering that successful induction of vaccine responses requires DC involvement, the failure of multiple malaria vaccines when transitioning from naïve populations to endemic populations $(21,150)$ may be due to impaired DC function in these endemic populations prior to vaccination.

Some valuable insights could be obtained by investigating differences in DC impairment between asymptomatic and symptomatic malaria cases. The systemic inflammation characteristic of symptomatic malaria undoubtedly contributes to DC dysfunction. While asymptomatic cases seem to experience similar loss of DC function short-term $(87,88,99)$, it may be that they exhibit better recovery of DC function longterm. The phenotypic differences between high- and low-dose inoculation cohorts in CHMI studies $(89,91,92)$ suggest that administering curative treatment while parasitaemia is still very low is also effective at limiting DC impairment. The similarities between naturally infected cohorts (Figure 3) also suggest that transmission intensity does not have a major impact on DC dysfunction beyond a certain threshold. Studies that follow the long-term effects of malaria exposure on DC function will be essential to clarify whether DC impairment persists after malaria elimination, especially in unstable transmission settings.

Variations in methodology have made it difficult to ascertain the effects Plasmodium parasites have on DCs in vitro. Particularly, care must be taken when stating that P. falciparum "suppresses" DC function in vitro: levels of activation lower than that seen in response to positive controls is not necessarily indicative of suppression. True suppression should be defined by an inability of DCs to become activated by known activatory stimuli, particularly pattern recognition receptor ligands. Analyses should also always account for increased cell death, which may result in false reports of suppression. Overall, the data indicates that DC function is not universally suppressed (Figure 3). Rather, Plasmodium appears to target specific pathways, among them the ones crucial for inducing 


\section{Ex vivo blood DC responses to natural and experimental Plasmodium infection \\ $\downarrow$ Peripheral DC numbers \\ $\uparrow$ DC apoptosis \\ $\uparrow$ Peripheral BDCA $-3^{+} \mathrm{CDC} 1$ \\ $\downarrow$ DC phagocytosis \\ $\downarrow$ Allogeneic T cell stimulation \\ $\downarrow$ HLA-DR (all DCs) \\ CD86 (pDCs only)}

\section{In vitro DC responses to Plasmodium stimuli}

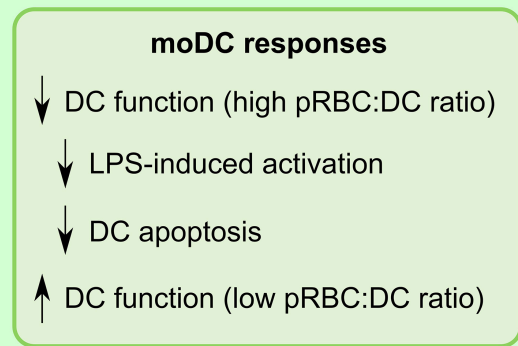

\section{Bona fide DC responses}

$\uparrow$ DC activation (pRBCs, merozoites)

Requirement for pDC-cDC cross-talk

in response to parasites
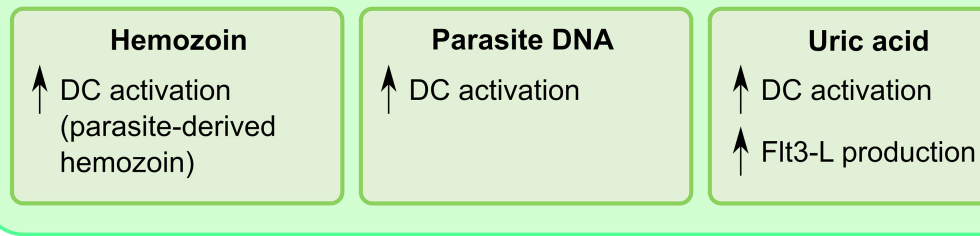

FIGURE 3 | A summary of dendritic cell responses to Plasmodium. While the dendritic cell response is heterogeneous, certain trends are evident when examining the entirety of the current literature. Downregulation of dendritic cell function is commonly observed in field studies of infected humans. In vitro studies have yielded insight into the complexities of dendritic cell activation by Plasmodium, particularly the types of ligands that can trigger an inflammatory response.

naïve $\mathrm{T}$ cell proliferation $(82,103,104)$, while still allowing DCs to polarize responses toward a $\mathrm{T}_{\mathrm{H}}$ 1-like phenotype $(85,106)$. Research into whether the functionality of these $\mathrm{T}$ cells is affected relative to other pathogens which induce $\mathrm{T}_{\mathrm{H}} 1$ polarization will be important to understand the uniquely Plasmodium factors that delay the development of antimalarial immunity.

There also appears to be an important role for DC cross-talk between pDC and cDC subsets $(85,107)$. This has two crucial implications: first, it warrants further study of how individual DC subsets respond to Plasmodium spp. without grouping them into a monolithic conglomeration of $\mathrm{HLA}-\mathrm{DR}^{\mathrm{hi}} \mathrm{Lin}^{-}$cells. In particular, elevation of the circulating BDCA- $3^{+} \mathrm{cDC} 1$ subset is a commonly reported phenomenon in field studies but, due to the low frequencies of this rare population, its function in malaria has not been extensively investigated. More rigorous strategies, including cell sorting, should be employed to study how purified subsets respond to malaria. Secondly, pDC crosstalk is essential for production of cytokines such as CXCL10 and IFN- $\alpha$. CXCL10, also known as IP-10, is majorly implicated in malaria pathogenesis (151-153), and IFN- $\alpha$ has recently been shown to downregulate antimalarial immunity $(154,155)$. As pDC help is required for production of both of these cytokines, and $\mathrm{pDCs}$ are the major producers of IFN- $\alpha$ in malaria $(65,155)$, strategies to reduce pDC activation in malaria might be beneficial for the longevity of antimalarial immunity. Moreover, malarial DNA has proven to be a potent inflammatory ligand $(107,136)$, and since only pDCs express TLR9 in humans (118), detection of malarial DNA by pDCs may play a significant role in detrimental cytokine responses, making $\mathrm{pDCs}$ an ideal target for strategies to reduce pathogenicity.

Moreover, ex vivo and in vitro studies depict a complex effect of malaria on the pDC subset. Numbers of circulating pDCs were reduced during natural infection $(83,84,86,97,99)$ and CHMI $(92,95)$, though it is unclear whether this is due to $\mathrm{pDC}$ death or sequestration. One murine study indicated that pDC could be infected with or endocytose parasites (156). Whether a similar situation exists for human $\mathrm{pDC}$ is not known, but it is plausible that large numbers of parasites within $\mathrm{pDC}$ could kill these cells, leading to lower circulating numbers. Malaria infection also triggers the upregulation of CCR7 on pDCs (83), suggesting that homing to lymphoid tissues is enhanced during infection. Thus, circulating pDCs may not be the subsets responding to infection, which could explain why pDC activation has not been reported in most field studies. Multiple other factors could also contribute to this perceived lack of pDC activation. Firstly, sustained parasitaemia in malariaendemic regions may downregulate expression of activatory ligands on circulating pDCs. Secondly, non-conservative gating of pDCs may misrepresent the activation state of this DC population. Thirdly, no field studies to date have measured IFN$\alpha$ production, which is a direct and functional read-out of $\mathrm{pDC}$ activation. In vitro studies have observed IFN- $\alpha$ production when pDCs were directly stimulated with parasite products $(83,85$, 107). This reinforces the need to study $\mathrm{pDC}$ function during malaria to understand whether a loss of $\mathrm{pDC}$ numbers in the periphery is associated with a concomitant loss of function.

When interpreting existing literature, it must be kept in mind that the majority of studies have focused on pRBCs and only a minority have examined responses to extracellular forms of the parasite such as merozoites. Considering that DC responses change depending on the parasite life stage $(85,105,107)$, even within the relatively limited scope of the blood stages, it will be vital to study the differences between responses to each life stage. Since it is unlikely that a single vaccine will be able to target the entire Plasmodium life cycle, understanding the type of responses induced by each life stage is essential for designing new 
TABLE 3 | Research priorities in DCs and malaria.

Priority
Understanding DC functionality to
improve malaria vaccines
Correlating DC function in malaria to
protection

Understanding the mechanism of DC modulation by Plasmodium spp.

\section{Approach}

In vitro assays to understand which DC signaling pathways are activated or unaffected by malaria and exploit adjuvant technologies that target these pathways

Incorporating DC functional assays into vaccine trials as a measure of vaccine relevance and functionality

Controlled human malaria infection studies in naïve and previously exposed cohorts to understand how DC responses are altered by prior exposure and how this correlates with clinical immunity

In-depth data analyses of how changes in DC phenotypes correlate with protective immune responses and/or overall clinical immunity

Development of small animal or in vitro models to assess human DC responses

Thorough mapping of the functional and transcriptional changes that DC undergo upon encountering Plasmodium spp.

Measuring DC responses to different Plasmodium life stages and determining which life stages have the greatest immunostimulatory potential to facilitate vaccine development therapeutic interventions to protect the host against damaging immunopathology. A two-pronged "big data" approach could be particularly informative, with the use of RNAseq or proteomics on the DC side to examine immune pathways induced by each parasite life stage, and conversely a proteomics or otheromics-based approach examining the potential immunogens expressed by each parasite life stage. In particular, understanding the pattern recognition receptor signaling pathways which are inhibited or activated by pRBCs would enable more targeted therapies to reverse their suppressive effects. This would inform functional studies, and therefore form a roadmap for vaccine strategies or other therapeutic approaches that could induce potent, long-lasting antimalarial immunity.

A primary caveat of the current literature on human DC responses to malaria, particularly in field studies of infected individuals, is that all studies have looked at circulating blood DCs. It may be that mature DCs migrate into the tissues while immature DCs remain in circulation. Therefore, care should be taken not to generalize the phenotype of these circulating DCs to the responses of liver, spleen or bone marrow tissueresident DCs, which may have greater functional relevance. Understandably, obtaining tissue-resident cells directly from humans is difficult and ethically challenging. Thus, models such as humanized mice, which produce DCs functionally similar to those found in humans $(57,157)$, are a promising system to study DCs with a tissue-resident phenotype. While a humanized mouse that is able to support the entire Plasmodium life cycle is still out of reach, recent technological improvements have enabled development of models that allow study of immunity to specific life stages [reviewed in (158)]. For example, humanized liver mice could shed light on the elusive phenomenon of liverstage immunity, while mice with humanized immune systems could provide better insight into cell-mediated mechanisms of protection against the blood stage. Development of a complete humanized mouse model for Plasmodium would be invaluable for human immunological research and vaccine development.

Organoids, miniature models of organ function, have proven useful in studying tissues such as the liver (159) and intestine (160). An intestinal organoid model has already been used to study transcriptomic regulation of another Apicomplexan with a complex life cycle, Cryptosporidium (161). Development of a splenic organoid could be used for development of functional tissue DCs and enable further study of blood-stage malaria, as well as other blood-borne diseases (162). Liver and skin organoids would also be invaluable for studying the presymptomatic phase of the life cycle, and aid development of a vaccine that confers sterile immunity.

Finally, data from in vitro studies using moDCs as a model may not be representative of the interactions between Plasmodium and steady-state DCs. Both moDCs and bona fide DCs show pro- and non-inflammatory responses to Plasmodium stimulation, but phenotypic and transcriptomic differences between them highlight that the moDC phenotype is pronouncedly different and may not necessarily be generalizable (125). It was previously thought that moDCs might be analogous to $\mathrm{CD} 16^{+}$DCs. However, recent findings outline that moDCs and $\mathrm{CD}_{16}{ }^{+} \mathrm{DCs}$ exist as separate populations in the steady-state $(124,125)$, and while they may have convergent functions during inflammation, this has not yet been conclusively shown. Therefore, caution should be taken when describing DC-parasite interactions using results generated with moDCs: while it is likely that moDC-like APCs are generated during the course of Plasmodium infection, moDCs may not accurately reflect the behavior of steady-state DC populations.

This review has outlined many facets of DC function in malaria that are not well understood (Table 3). Firstly, DCs from naïve individuals appear to respond differently to each malaria life stage. These responses should be compared to those seen in exposed individuals for a better understanding of how prolonged malaria exposure affects immune recognition. Secondly, we must further develop an understanding of how the DC phenotypes we observe ex vivo and in vitro translate into effectiveness, duration, and quality of antimalarial responses. Including DC studies in vaccine trials would help to address which elements best describe a beneficial DC response. This should be supplemented by more studies of DCs in natural infection against comparable nonexposed donors. Thirdly, there is a need for better models to examine DC function in malaria. DC studies of the future should focus as much as possible upon bona fide DCs, and seek to 
develop new models that will permit a more in-depth study of how DC function is altered by the malaria parasite.

To conclude, the complexities of DCs make them a relatively understudied cell type in the context of malaria, where they have a potentially pivotal role in the regulation of antimalarial immunity. Many gaps in knowledge remain to be addressed, and there is a prominent need for novel technologies to bridge the gap. A deeper, more rigorous understanding of how ex vivo and in vitro Plasmodium-exposed DC phenotypes correlate with effective immunity, and the mechanisms that regulate DC interactions with Plasmodium will grant valuable insight into the acquisition of immunity, and form a basis for the development of better vaccines.

\section{AUTHOR CONTRIBUTIONS}

XZY wrote the first draft of the manuscript, which was reviewed and edited by RJL, JGB, and MOK. XZY and RJL

\section{REFERENCES}

1. Laveran A. Un Nouveau Parasite Trouvé Dans le Sang de Malades Atteints de Fièvre Palustre: Origine Parasitaire des Accidents de Limpaludisme. Paris: Bulletins et mémoires de la Société Médicale des Hôpitaux (1881) p. $158-64$.

2. Grassi B. Studi di uno Zoologo Sulla Malaria. Rome: R. Accademia dei Lincei. (1900). Available online at: https://archive.org/details/ studidiunozoolog00gras/page/n8

3. Shortt HE, Garnham PCC. The pre-erythrocytic stage of human malaria, Plasmodium vivax. Br Med J. (1948) 1:547.

4. Shortt HE, Fairley NH, Covell G, Shute PG, Garnham PCC. Preerythrocytic stage of Plasmodium falciparum. BMJ. (1949) 2:1006-1008. doi: 10.1136/bmj.2.4635.1006

5. Florens L, Washburn MP, Raine JD, Anthony RM, Grainger M, Haynes JD, et al. A proteomic view of the Plasmodium falciparum life cycle. Nature. (2002) 419:520-6. doi: 10.1038/nature01107

6. Bejon P, Andrews L, Andersen RF, Dunachie S, Webster D, Walther M, et al. Calculation of liver-to-blood inocula, parasite growth rates, and preerythrocytic vaccine efficacy, from serial quantitative polymerase chain reaction studies of volunteers challenged with malaria sporozoites. J Infect Dis. (2005) 191:619-26. doi: 10.1086/427243

7. Krotoski W. Discovery of the hypnozoite and a new theory of malarial relapse. Trans R Soc Trop Med Hyg. (1985) 79:1-11.

8. Mueller I, Galinski MR, Baird JK, Carlton JM, Kochar DK, Alonso PL, et al. Key gaps in the knowledge of Plasmodium vivax, a neglected human malaria parasite. Lancet Infect Dis. (2009) 9:555-66. doi: 10.1016/S1473-3099(09)70177-X

9. Cowman AF, Crabb BS. Invasion of red blood cells by malaria parasites. Cell. (2006) 124:755-66. doi: 10.1016/j.cell.2006.02.006

10. McMillan PJ, Millet C, Batinovic S, Maiorca M, Hanssen E, Kenny S, et al. Spatial and temporal mapping of the PfEMP1 export pathway in Plasmodium falciparum. Cell Microbiol. (2013) 15:1401-18. doi: 10.1111/cmi. 12125

11. Thomson D. I.-A research into the production, life and death of crescents in malignant tertian malaria, in treated and untreated cases, by an enumerative method. Ann Trop Med Parasitol. (1911) 5:57-81. doi: 10.1080/00034983.1911.11686341

12. Day KP, Hayward RE, Dyer M. The biology of Plasmodium falciparum transmission stages. Parasitology. (1998) 116(Suppl.):S95-109.

13. Boyd M, Kitchen S. On the infectiousness of patients infected with Plasmodium vivax and Plasmodium falciparum. Am J Trop Med Hyg. (1937) 17:253-62. prepared tables and figures. All authors have read and revised the manuscript.

\section{FUNDING}

Funding was provided by NHMRC (Senior Research Fellowships to JGB and MOK; Early Career Fellowship to RJL; Program Grant to JGB; Project grant to MOK). Burnet Institute was supported by the NHMRC Independent Research Institutes Support Scheme and a Victorian State Government Operational Infrastructure Grant. JGB is a member of the Australian Center for Research Excellence in Malaria Elimination (ACREME), funded by the NHMRC.

\section{ACKNOWLEDGMENTS}

We would like to thank Ms. G. Stuart for providing graphical elements for Figure 1.

14. McKenzie FE, Jeffery GM, Collins WE. Gametocytemia and fever in human malaria infections. J Parasitol. (2007) 93:627-33. doi: 10.1645/GE-1052R.1

15. Smalley ME, Abdalla S, Brown J. The distribution of Plasmodium falciparum in the peripheral blood and bone marrow of Gambian children. Trans R Soc Trop Med Hyg. (1981) 75:103-5.

16. Thomson D. The origin and development of gametes (Crescents) in malignant tertian malaria: some observations on flagellation, etc. Ann Trop Med Parasitol. (1914) 8:85-104. doi: 10.1080/00034983.1914.11687643

17. Thomson JG, Robertson A. The structure and development of plasmodium falciparum gametocytes in the internal organs and peripheral circulation. Trans $R$ Soc Trop Med Hyg. (1935) 29:31-40. doi: 10.1016/S0035-9203(35)90015-3

18. Lensen A, Bril A, van de Vegte M, van Gemert GJ, Eling W, Sauerwein R. Plasmodium falciparum: infectivity of cultured, synchronized gametocytes to mosquitoes. Exp Parasitol. (1999) 103:101-3. doi: 10.1006/expr.1998.4354

19. Cohen S, McGregor IA, Carrington SP. Gamma-globulin and acquired immunity to human malaria. Nature. (1961) 192:733-7. doi: $10.1038 / 192733 \mathrm{a} 0$

20. Fowkes FJI, Boeuf P, Beeson JG. Immunity to malaria in an era of declining malaria transmission. Parasitology. (2016) 143:139-53. doi: 10.1017/S0031182015001249

21. Olotu A, Fegan G, Wambua J, Nyangweso G, Leach A, Lievens M, et al. Seven-year efficacy of RTS,S/AS01 malaria vaccine among young African children. N Engl J Med. (2016) 374:2519-29. doi: 10.1056/NEJMoa1515257

22. Neafsey DE, Juraska M, Bedford T, Benkeser D, Valim C, Griggs A, et al. Genetic diversity and protective efficacy of the RTS,S/AS01 malaria vaccine. N Engl J Med. (2015) 373:2025-37. doi: 10.1056/NEJMoa1505819

23. White MT, Verity R, Griffin JT, Asante KP, Owusu-Agyei S, Greenwood B, et al. Immunogenicity of the RTS,S/AS01 malaria vaccine and implications for duration of vaccine efficacy: Secondary analysis of data from a phase 3 randomised controlled trial. Lancet Infect Dis. (2015) 15:1450-8. doi: 10.1016/S1473-3099(15)00239-X

24. Freudenthal PS, Steinman RM. The distinct surface of human blood dendritic cells, as observed after an improved isolation method. Proc Natl Acad Sci USA. (1990) 87:7698-702. doi: 10.1073/pnas.87.19.7698

25. Orsini G, Legitimo A, Failli A, Massei F, Biver P, Consolini R. Enumeration of human peripheral blood dendritic cells throughout the life. Int Immunol. (2012) 24:347-56. doi: 10.1093/intimm/dxs006

26. Chen XQ, Liu XF, Liu WH, Guo W, Yu Q, Wang CY. Comparative analysis of dendritic cell numbers and subsets between smoking and control subjects in the peripheral blood. Int J Clin Exp Pathol. (2013) 6:290-6.

27. Macri C, Pang ES, Patton T, O’Keeffe M. Dendritic cell subsets. Semin Cell Dev Biol. (2018) 84:11-21. doi: 10.1016/j.semcdb.2017.12.009 
28. Dzionek A, Fuchs A, Schmidt P, Zysk M, Miltenyi S, Buck DW, et al. BDCA-2, BDCA-3, and BDCA-4: three markers for distinct subsets of dendritic cells in human peripheral blood. J Immunol. (2000) 165:6037-46. doi: 10.4049/jimmunol.165.11.6037

29. Summers KL, Hock BD, McKenzie JL, Hart DN. Phenotypic characterization of five dendritic cell subsets in human tonsils. Am J Pathol. (2001) 159:28595. doi: 10.1016/S0002-9440(10)61694-X

30. MacDonald KPA, Munster DJ, Clark GJ, Dzionek A, Schmitz J, Hart DNJ, et al. Characterization of human blood dendritic cell subsets. Blood. (2002) 100:4512-20. doi: 10.1182/blood-2001-11-0097

31. Hambleton S, Salem S, Bustamante J, Bigley V, Boisson-Dupuis S, Azevedo J, et al. IRF8 mutations and human dendritic-cell immunodeficiency. $N$ Engl J Med. (2011) 365:127-38. doi: 10.1056/NEJMoa1100066

32. Meera S, Madhuri T, Manisha G, Ramesh P. Irreversible loss of pDCs by apoptosis during early HIV infection may be a critical determinant of immune dysfunction. Viral Immunol. (2010) 23:241-9. doi: 10.1089/vim.2009.0112

33. Ku C-L, von Bernuth H, Picard C, Zhang S-Y, Chang H-H, Yang K, et al. Selective predisposition to bacterial infections in IRAK-4-deficient children: IRAK-4-dependent TLRs are otherwise redundant in protective immunity. $J$ Exp Med. (2007) 204:2407-22. doi: 10.1084/jem.20070628

34. Bigley V, Haniffa M, Doulatov S, Wang X-N, Dickinson R, McGovern N, et al. The human syndrome of dendritic cell, monocyte, B and NK lymphoid deficiency. J Exp Med. (2011) 208:227-34. doi: 10.1084/jem.20101459

35. da Silva HB, Caetano SS, Monteiro I, Gómez-Conde I, Hanson K, Penha-Gonçalves C, et al. Early skin immunological disturbance after Plasmodium-infected mosquito bites. Cell Immunol. (2012) 277:22-32. doi: 10.1016/j.cellimm.2012.06.003

36. Vichchathorn P, Jenwithisuk R, Leelaudomlipi S, Tungpradabkul S, Hongeng $\mathrm{S}$, Cui $\mathrm{L}$, et al. Induction of specific immune responses against the Plasmodium vivax liver-stage via in vitro activation by dendritic cells. Parasitol Int. (2006) 55:187-93. doi: 10.1016/j.parint.2006.04.001

37. Menezes RG, Pant S, Kharoshah MA, Senthilkumaran S, Arun M, Nagesh $\mathrm{KR}$, et al. Autopsy discoveries of death from malaria. Leg Med. (2012) 14:111-115. doi: 10.1016/j.legalmed.2012.01.007

38. Farfour E, Charlotte F, Settegrana C, Miyara M, Buffet P. The extravascular compartment of the bone marrow: a niche for Plasmodium falciparum gametocyte maturation? Malar J. (2012) 11:285. doi: 10.1186/1475-2875-11-285

39. Rogers NJ, Hall BS, Obiero J, Targett G a, Sutherland CJ. A model for sequestration of the transmission stages of Plasmodium falciparum: adhesion of gametocyte-infected erythrocytes to human bone marrow cells. Infect Immun. (2000) 68:3455-62. doi: 10.1128/IAI.68.6.3455-3462.2000

40. Malleret B, Li A, Zhang R, Tan KSW, Suwanarusk R, Claser C, et al. Plasmodium vivax: restricted tropism and rapid remodeling of CD71-positive reticulocytes. Blood. (2015) 125:1314-1324. doi: 10.1182/blood-2014-08-596015

41. Obaldia N, Meibalan E, Sa JM, Ma S, Clark MA, Mejia P, et al. Bone marrow is a major parasite reservoir in Plasmodium vivax infection. MBio. (2018) 9:e00625-18. doi: 10.1128/mBio.00625-18

42. Xia S, Guo Z, Xu X, Yi H, Wang Q, Cao X. Hepatic microenvironment programs hematopoietic progenitor differentiation into regulatory dendritic cells, maintaining liver tolerance. Blood. (2008) 112:3175-85. doi: 10.1182/blood-2008-05-159921

43. Goddard S, Youster J, Morgan E, Adams DH. Interleukin-10 secretion differentiates dendritic cells from human liver and skin. Am J Pathol. (2004) 164:511-9. doi: 10.1016/S0002-9440(10)63141-0

44. Mittag D, Proietto AI, Loudovaris T, Mannering SI, Vremec D, Shortman $\mathrm{K}$, et al. Human dendritic cell subsets from spleen and blood are similar in phenotype and function but modified by donor health status. I Immunol. (2011) 186:6207-17. doi: 10.4049/jimmunol.1002632

45. Hopp CS, Chiou K, Ragheb DRT, Salman AM, Khan SM, Liu AJ, et al. Longitudinal analysis of plasmodium sporozoite motility in the dermis reveals component of blood vessel recognition. Elife. (2015) 4:1-21. doi: 10.7554/eLife.07789

46. Roestenberg M, Teirlinck AC, McCall MBB, Teelen K, Makamdop KN, Wiersma J, et al. Long-term protection against malaria after experimental sporozoite inoculation: an open-label follow-up study. Lancet. (2011) 377:1770-6. doi: 10.1016/S0140-6736(11)60360-7

47. Roestenberg M, McCall MBB, Hopman J, Wiersma J, Luty AJF, van Gemert GJ, et al. Protection against a malaria challenge by sporozoite inoculation. $N$ Engl J Med. (2009) 361:468-77. doi: 10.1056/NEJMoa0805832

48. Bijker EM, Teirlinck AC, Schats R, Van Gemert GJ, Van De Vegte-Bolmer M, Van Lieshout L, et al. Cytotoxic markers associate with protection against malaria in human volunteers immunized with plasmodium Falciparum Sporozoites. J Infect Dis. (2014) 210:1605-15. doi: 10.1093/infdis/jiu293

49. Amino R, Thiberge S, Martin B, Celli S, Shorte S, Frischknecht F, et al. Quantitative imaging of Plasmodium transmission from mosquito to mammal. Nat Med. (2006) 12:220-4. doi: 10.1038/nm1350

50. Chakravarty S, Cockburn IA, Kuk S, Overstreet MG, Sacci JB, Zavala F. CD8+ $\mathrm{T}$ lymphocytes protective against malaria liver stages are primed in skin-draining lymph nodes. Nat Med. (2007) 13:1035-41. doi: $10.1038 / \mathrm{nm} 1628$

51. Leiriao P, Mota MM, Rodriguez A. Apoptotic Plasmodium- infected hepatocytes provide antigens to liver dendritic cells. J Infect Dis. (2005) 191:1576-81. doi: 10.1086/429635

52. Bamboat ZM, Stableford JA, Plitas G, Burt BM, Nguyen HM, Welles AP, et al. Human liver dendritic cells promote T cell hyporesponsiveness. J Immunol. (2009) 182:1901-11. doi: 10.4049/jimmunol.0803404

53. Pillarisetty VG, Shah AB, Miller G, Bleier JI, DeMatteo RP. Liver dendritic cells are less immunogenic than spleen dendritic cells because of differences in subtype composition. J Immunol. (2004) 172:1009-17. doi: 10.4049/jimmunol.172.2.1009

54. Bosma BM, Metselaar HJ, Mancham S, Boor PPC, Kusters JG, Kazemier $\mathrm{G}$, et al. Characterization of human liver dendritic cells in liver grafts and perfusates. Liver Transplant. (2006) 12:384-93. doi: 10.1002/lt.20659

55. Sack BK, Mikolajczak SA, Fishbaugher M, Vaughan AM, Flannery EL, Nguyen T, et al. Humoral protection against mosquito bite-transmitted Plasmodium falciparum infection in humanized mice. Npj Vaccines. (2017) 2:27. doi: 10.1038/s41541-017-0028-2

56. Yang ASP, O’Neill MT, Jennison C, Lopaticki S, Allison CC, Armistead JS, et al. Cell traversal activity is important for Plasmodium falciparum liver infection in humanized mice. Cell Rep. (2017) 18:3105-16. doi: 10.1016/j.celrep.2017.03.017

57. Ding Y, Wilkinson A, Idris A, Fancke B, O’Keeffe M, Khalil D, et al. FLT3ligand treatment of humanized mice results in the generation of large numbers of CD141+ and CD1c+ dendritic cells in vivo. J Immunol. (2014) 192:1982-9. doi: 10.4049/jimmunol.1302391

58. Aguilar R, Magallon-Tejada A, Achtman AH, Moraleda C, Joice R, Cisteró P, et al. Molecular evidence for the localization of Plasmodium falciparum immature gametocytes in bone marrow. Blood. (2014) 123:95966. doi: 10.1182/blood-2013-08-520767

59. Joice R, Nilsson SK, Montgomery J, Dankwa S, Egan E, Morahan B, et al. Plasmodium falciparum transmission stages accumulate in the human bone marrow. Sci Transl Med. (2014) 6:244re5. doi: 10.1126/scitranslmed.3008882

60. Wickramasinghe SN, Phillips RE, Looareesuwan S, Warrell DA, Hughes M. The bone marrow in human cerebral malaria: parasite sequestration within sinusoids. Br J Haematol. (1987) 66:295-306.

61. Ru Y, Mao B-Y, Zhang F, Pang T, Zhao S, Liu J, et al. Invasion of erythroblasts by Pasmodium vivax: a new mechanism contributing to malarial anemia. Ultrastruct Pathol. (2009) 33:236-42. doi: 10.3109/01913120903251643

62. Avril M, Brazier AJ, Melcher M, Sampath S, Smith JD. DC8 and DC13 var genes associated with severe malaria bind avidly to diverse endothelial cells. PLoS Pathog. (2013) 9:e1003430. doi: 10.1371/journal.ppat.1003430

63. Reeves RK, Fultz PN. Characterization of plasmacytoid dendritic cells in bone marrow of pig-tailed macaques. Clin Vaccine Immunol. (2008) 15:3541. doi: 10.1128/CVI.00309-07

64. Feuerer M, Beckhove P, Garbi N, Mahnke Y, Limmer A, Hommel M, et al. Bone marrow as a priming site for T-cell responses to blood-borne antigen. Nat Med. (2003) 9:1151-7. doi: 10.1038/nm914

65. Spaulding E, Fooksman D, Moore JM, Saidi A, Feintuch CM, Reizis B, et al. STING-licensed macrophages prime type I IFN production by plasmacytoid dendritic cells in the bone marrow during severe Plasmodium yoelii malaria. PLoS Pathog. (2016) 12:e1005975. doi: 10.1371/journal.ppat.1005975 
66. Junqueira C, Barbosa CRR, Costa PAC, Teixeira-Carvalho A, Castro G, Sen Santara S, et al. Cytotoxic CD8+T cells recognize and kill Plasmodium vivax-infected reticulocytes. Nat Med. (2018) 24:1330-6. doi: 10.1038/s41591-018-0117-4

67. M Eriksson E, Sampaio NG, Schofield L. Toll-like receptors and malaria - sensing and susceptibility. J Trop Dis. (2013) 2:1-7. doi: 10.4172/2329-891X.1000126

68. Gazzinelli RT, Kalantari P, Fitzgerald KA, Golenbock DT. Innate sensing of malaria parasites. Nat Rev Immunol. (2014) 14:744-57. doi: 10.1038/nri3742

69. Trubowitz S, Masek B. Plasmodium falciparum: phagocytosis by polymorphonuclear leukocytes. Science. (1968) 162:273-4. doi: $10.1126 /$ science. 162.3850 .273

70. Chan J, Howell KB, Reiling L, Ataide R, Mackintosh CL, Fowkes FJI, et al. Targets of antibodies against Plasmodium falciparum-infected erythrocytes in malaria immunity. J Clin Invest. (2012) 122:3227-38. doi: $10.1172 /$ JCI62182

71. Urban BC, Willcox N, Roberts DJ. A role for CD36 in the regulation of dendritic cell function. Proc Natl Acad Sci USA. (2001) 98:8750-5. doi: 10.1073/pnas.151028698

72. Miller LH, Baruch DI, Marsh K, Doumbo OK. The pathogenic basis of malaria. Nature. (2002) 415:673-9. doi: 10.1038/415673a

73. Lundie RJ, de Koning-Ward TF, Davey GM, Nie CQ, Hansen DS, Lau LS, et al. Blood-stage Plasmodium infection induces CD8+ T lymphocytes to parasite-expressed antigens, largely regulated by CD8alpha+ dendritic cells. Proc Natl Acad Sci USA. (2008) 105:14509-14. doi: 10.1073/pnas.0806727105

74. Jung S, Unutmaz D, Wong P, Sano G-I, De los Santos K, Sparwasser T, et al. In vivo depletion of $\mathrm{CD} 11 \mathrm{c}+$ dendritic cells abrogates priming of $\mathrm{CD} 8+$ $\mathrm{T}$ cells by exogenous cell-associated antigens. Immunity. (2002) 17:211-20. doi: 10.1016/S1074-7613(02)00365-5

75. Voisine C, Mastelic B, Sponaas AM, Langhorne J. Classical CD11c+ dendritic cells, not plasmacytoid dendritic cells, induce $\mathrm{T}$ cell responses to Plasmodium chabaudi malaria. Int J Parasitol. (2010) 40:711-9. doi: 10.1016/j.ijpara.2009.11.005

76. Ocaña-Morgner C, Mota MM, Rodriguez A. Malaria blood stage suppression of liver stage immunity by dendritic cells. J Exp Med. (2003) 197:143-51. doi: 10.1084 /jem. 20021072

77. Wilson NS, Behrens GMN, Lundie RJ, Smith CM, Waithman J, Young L, et al. Systemic activation of dendritic cells by Toll-like receptor ligands or malaria infection impairs cross-presentation and antiviral immunity. Nat Immunol. (2006) 7:165-72. doi: 10.1038/ni1300

78. Millington OR, Gibson VB, Rush CM, Zinselmeyer BH, Phillips RS, Garside $\mathrm{P}$, et al. Malaria impairs $\mathrm{T}$ cell clustering and immune priming despite normal signal 1 from dendritic cells. PLoS Pathog. (2007) 3:1380-7. doi: 10.1371/journal.ppat.0030143

79. Lundie RJ, Young LJ, Davey GM, Villadangos J a, Carbone FR, Heath WR, et al. Blood-stage Plasmodium berghei infection leads to short-lived parasiteassociated antigen presentation by dendritic cells. Eur J Immunol. (2010) 40:1674-81. doi: 10.1002/eji.200939265

80. Piva L, Tetlak P, Claser C, Karjalainen K, Renia L, Ruedl C. Cutting edge: Clec9A + dendritic cells mediate the development of experimental cerebral malaria. J Immunol. (2012) 189:1128-32. doi: 10.4049/jimmunol.1201171

81. deWalick S, Amante FH, McSweeney K a, Randall LM, Stanley AC, Haque A, et al. Cutting edge: conventional dendritic cells are the critical APC required for the induction of experimental cerebral malaria. J Immunol. (2007) 178:6033-7. doi: 10.4049/jimmunol.178. 10.6033

82. Urban BC, Mwangi T, Ross A, Kinyanjui S, Mosobo M, Kai $\mathrm{O}$, et al. Peripheral blood dendritic cells in children with acute Plasmodium falciparum malaria. Blood. (2001) 98:2859-61. doi: 10.1182/blood.V98.9.2859

83. Pichyangkul S, Yongvanitchit K, Kum-arb U, Hemmi H, Akira S, Krieg AM, et al. Malaria blood stage parasites activate human plasmacytoid dendritic cells and murine dendritic cells through a Toll-like receptor 9-dependent pathway. J Immunol. (2004) 172:4926-33. doi: 10.4049/jimmunol.172.8.4926

84. Pinzon-Charry A, Woodberry T, Kienzle V, McPhun V, Minigo G, Lampah DA, et al. Apoptosis and dysfunction of blood dendritic cells in patients with falciparum and vivax malaria. J Exp Med. (2013) 210:1635-46. doi: $10.1084 /$ jem. 20121972
85. Götz A, Tang MS, Ty MC, Arama C, Ongoiba A, Doumtabe D, et al. Atypical activation of dendritic cells by Plasmodium falciparum. Proc Natl Acad Sci USA. (2017) 114:E10568-77. doi: 10.1073/pnas.1708383114

86. Jangpatarapongsa K, Chootong P, Sattabongkot J, Chotivanich K, Sirichaisinthop J, Tungpradabkul S, et al. Plasmodium vivax parasites alter the balance of myeloid and plasmacytoid dendritic cells and the induction of regulatory T cells. Eur J Immunol. (2008) 38:2697-705. doi: 10.1002/eji.200838186

87. Kho S, Marfurt J, Noviyanti R, Kusuma A, Piera KA, Burdam FH, et al., Preserved dendritic cell HLA-DR expression and reduced regulatory T cell activation in asymptomatic Plasmodium falciparum and $P$. vivax infection. Infect Immun. (2015) 83:3224-32. doi: 10.1128/IAI.00226-15

88. Kho S, Marfurt J, Handayuni I, Pava Z, Noviyanti R, Kusuma A, et al. Characterization of blood dendritic and regulatory $\mathrm{T}$ cells in asymptomatic adults with sub-microscopic Plasmodium falciparum or Plasmodium vivax infection. Malar J. (2016) 15:328. doi: 10.1186/s12936-016-1382-7

89. Woodberry T, Minigo G, Piera K a, Amante FH, Pinzon-Charry A, Good MF, et al. Low-level Plasmodium falciparum blood-stage infection causes dendritic cell apoptosis and dysfunction in healthy volunteers. J Infect Dis. (2012) 206:333-40. doi: 10.1093/infdis/jis366

90. Teirlinck AC, Roestenberg M, Bijker EM, Hoffman SL, Sauerwein RW, Scholzen A. Plasmodium falciparum infection of human volunteers activates monocytes and CD16+ dendritic cells and induces upregulation of CD16 and CD1c expression. Infect Immun. (2015) 83:3732-9. doi: 10.1128/IAI.00473-15

91. Loughland JR, Minigo G, Burel J, Tipping PE, Piera KA, Amante FH, et al. Profoundly reduced CD1c + myeloid dendritic cell HLA-DR and CD86 expression and increased tumor necrosis factor production in experimental human blood-stage malaria infection. Infect Immun. (2016) 84:1403-12. doi: 10.1128/IAI.01522-15

92. Loughland JR, Minigo G, Sarovich DS, Field M, Tipping PE, Montes de Oca M, et al. Plasmacytoid dendritic cells appear inactive during sub-microscopic Plasmodium falciparum blood-stage infection, yet retain their ability to respond to TLR stimulation. Sci Rep. (2017) 7:2596. doi: 10.1038/s41598-017-02096-2

93. Loughland JR, Woodberry T, Boyle MJ, Tipping PE, Piera KA, Amante FH, et al. Plasmodium falciparum activates CD16+ dendritic cells to produce TNF and IL-10 in subpatent malaria. J Infect Dis. (2018) 219:660-71. doi: 10.1093/infdis/jiy555

94. Breitling LP, Fendel R, Mordmueller B, Adegnika AA, Kremsner PG, Luty AJF. Cord blood dendritic cell subsets in African newborns exposed to Plasmodium falciparum in utero. Infect Immun. (2006) 74:5725-9. doi: 10.1128/IAI.00682-06

95. Woodberry T, Loughland JR, Minigo G, Burel JG, Amante FH, Piera KA, et al. Early immune regulatory changes in a primary controlled human Plasmodium vivax infection: CD1c + myeloid dendritic cell maturation arrest, induction of the kynurenine pathway, and regulatory $\mathrm{T}$ cell activation. Infect Immun. (2017) 85:e00986-16. doi: 10.1128/IAI.00986-16

96. Urban BC, Cordery D, Shafi MJ, Bull PC, Newbold CI, Williams TN, et al. The frequency of BDCA3-positive dendritic cells is increased in the peripheral circulation of Kenyan children with severe malaria. Infect Immun. (2006) 74:6700-6. doi: 10.1128/IAI.00861-06

97. Diallo M, Aldebert D, Moreau J-C, Ndiaye M, Jambou R. Decrease of lymphoid dendritic cells in blood from malaria-infected pregnant women. Int J Parasitol. (2008) 38:1557-65. doi: 10.1016/j.ijpara.2008.04.013

98. Loharungsikul S, Troye-Blomberg M, Amoudruz P, Pichyangkul S, Yongvanitchit K, Looareesuwan S, et al. Expression of toll-like receptors on antigen-presenting cells in patients with falciparum malaria. Acta Trop. (2008) 105:10-5. doi: 10.1016/j.actatropica.2007.08.002

99. Gonçalves RM, Salmazi KC, Santos BAN, Bastos MS, Rocha SC, Boscardin $\mathrm{SB}$, et al. CD4+ CD25+ Foxp3+ regulatory $\mathrm{T}$ cells, dendritic cells, and circulating cytokines in uncomplicated malaria: do different parasite species elicit similar host responses? Infect Immun. (2010) 78:4763-72. doi: 10.1128/IAI.00578-10

100. Arama C, Giusti P, Boström S, Dara V, Traore B, Dolo A, et al. Interethnic differences in antigen-presenting cell activation and TLR responses in Malian children during Plasmodium falciparum malaria. PLoS ONE. (2011) 6:e18319. doi: 10.1371/journal.pone.0018319 
101. Ibitokou S, Oesterholt M, Brutus L, Borgella S, Agbowaï C, Ezinmègnon S, et al. Peripheral blood cell signatures of Plasmodium falciparum infection during pregnancy. PLoS ONE. (2012) 7:e49621. doi: 10.1371/journal.pone.0049621

102. Guermonprez P, Helft J, Claser C, Deroubaix S, Karanje H, Gazumyan A, et al. Inflammatory Flt3l is essential to mobilize dendritic cells and for T cell responses during Plasmodium infection. Nat Med. (2013) 19:730-8. doi: $10.1038 / \mathrm{nm} .3197$

103. Urban BC, Ferguson DJ, Pain A, Willcox N, Plebanski M, Austyn JM, et al. Plasmodium falciparum-infected erythrocytes modulate the maturation of dendritic cells. Nature. (1999) 400:73-7. doi: 10.1038/21900

104. Elliott SR, Spurck TP, Dodin JM, Maier AG, Voss TS, Yosaatmadja $\mathrm{F}$, et al. Inhibition of dendritic cell maturation by malaria is dose dependent and does not require Plasmodium falciparum erythrocyte membrane protein 1. Infect Immun. (2007) 75:3621-32. doi: 10.1128/IAI. 00095-07

105. Mukherjee P, Chauhan VS. Plasmodium falciparum-free merozoites and infected RBCs distinctly affect soluble CD40 ligand-mediated maturation of immature monocyte-derived dendritic cells. J Leukoc Biol. (2008) 84:244-54. doi: $10.1189 / \mathrm{jlb} .0807565$

106. Clemente AM, Fadigati G, Caporale R, Marchese DG, Castronovo G, Sannella AR, et al. Modulation of the immune and inflammatory responses by Plasmodium falciparum schizont extracts: role of myeloid dendritic cells in effector and regulatory functions of CD4+ lymphocytes. Infect Immun. (2013) 81:1842-51. doi: 10.1128/IAI.01226-12

107. Wu X, Gowda NM, Kumar S, Gowda DC. Protein-DNA complex is the exclusive malaria parasite component that activates dendritic cells and triggers innate immune responses. J Immunol. (2010) 184:4338-48. doi: 10.4049/jimmunol.0903824

108. Gowda NM, Wu X, Kumar S, Febbraio M, Gowda DC. CD36 contributes to malaria parasite-induced pro-inflammatory cytokine production and NK and T cell activation by dendritic cells. PLoS ONE. (2013) 8:e77604. doi: 10.1371/journal.pone.0077604

109. Fievet N, Varani S, Ibitokou S, Briand V, Louis S, Perrin RX, et al. Plasmodium falciparum exposure in utero, maternal age and parity influence the innate activation of foetal antigen presenting cells. Malar J. (2009) 8:1-12. doi: 10.1186/1475-2875-8-251

110. World Health Organisation. Guidelines of the Treatment of Malaria. Geneva (2010).

111. Bartoloni A, Zammarchi L. Clinical aspects of uncomplicated and severe malaria. Mediterr J Hematol Infect Dis. (2012) 4:e2012026. doi: 10.4084/MJHID.2012.026

112. Maraskovsky E, Brasel K, Teepe M, Roux ER, Lyman SD, Shortman K, et al. Dramatic increase in the numbers of functionally mature dendritic cells in Flt3 ligand-treated mice: multiple dendritic cell subpopulations identified. J Exp Med. (1996) 184:1953-62. doi: 10.1084/jem.184. 5.1953

113. Waskow C, Liu K, Darrasse-Jèze G, Guermonprez P, Ginhoux F, Merad $\mathrm{M}$, et al. The receptor tyrosine kinase Flt3 is required for dendritic cell development in peripheral lymphoid tissues. Nat Immunol. (2008) 9:676-83. doi: 10.1038/ni.1615

114. Umbers AJ, Aitken EH, Rogerson SJ. Malaria in pregnancy: small babies, big problem. Trends Parasitol. (2011) 27:168-75. doi: 10.1016/j.pt.2011.01.007

115. Elsayh KI, Zahran AM, Lotfy Mohamad I, Aly SS. Dendritic cells in childhood sepsis. J Crit Care. (2013) 28:881.e7-13. doi: 10.1016/j.jcrc.2013.05.007

116. Macatonia SE, Lau R, Patterson S, Pinching AJ, Knight SC. Dendritic cell infection, depletion and dysfunction in HIV-infected individuals. Immunology. (1990) 71:38-45.

117. Averill L, Lee WM, Karandikar NJ. Differential dysfunction in dendritic cell subsets during chronic HCV infection. Clin Immunol. (2007) 123:40-9. doi: 10.1016/j.clim.2006.12.001

118. Hémont C, Neel A, Heslan M, Braudeau C, Josien R. Human blood mDC subsets exhibit distinct TLR repertoire and responsiveness. J Leukoc Biol. (2013) 93:599-609. doi: 10.1189/jlb.0912452

119. Nebl T, de Veer M, Schofield L. Stimulation of innate immune responses by malarial glycosylphosphatidylinositol via pattern recognition receptors. Parasitology. (2005) 130(Suppl.):S45-62: doi: 10.1017/S0031182005008152
120. Coban C, Ishii KJ, Kawai T, Hemmi H, Sato S, Uematsu S, et al. Tolllike receptor 9 mediates innate immune activation by the malaria pigment hemozoin. J Exp Med. (2005) 201:19-25. doi: 10.1084/jem.20041836

121. World Health Organization. World Malaria Report 2018. Geneva (2018).

122. Kitchen $\mathrm{S}$. The infection of reticulocytes by Plasmodium vivax. Am J Trop Med Hyg. (1938) 1-18:347-59.

123. McCarthy JS, Sekuloski S, Griffin PM, Elliott S, Douglas N, Peatey C, et al. A pilot randomised trial of induced blood-stage Plasmodium falciparum infections in healthy volunteers for testing efficacy of new antimalarial drugs. PLoS ONE. (2011) 6:e21914. doi: 10.1371/journal.pone.0021914

124. Robbins SH, Walzer T, Dembélé D, Thibault C, Defays A, Bessou G, et al. Novel insights into the relationships between dendritic cell subsets in human and mouse revealed by genome-wide expression profiling. Genome Biol. (2008) 9:R17. doi: 10.1186/gb-2008-9-1-r17

125. Collin M, Bigley V. Human dendritic cell subsets: an update. Immunology. (2018) 154:3-20. doi: 10.1111/imm.12888

126. Villani A-C, Satija R, Reynolds G, Sarkizova S, Shekhar K, Fletcher J, et al. Single-cell RNA-seq reveals new types of human blood dendritic cells, monocytes, and progenitors. Science. (2017) 356:eaah4573. doi: $10.1126 /$ science.aah4573

127. Steinman RM. The Dendritic Cell System and its Role in Immunogenicity. Annu Rev Immunol. (1991) 9:271-96. doi: 10.1146/annurev.iy.09.040191.001415

128. Jongbloed SL, Kassianos AJ, McDonald KJ, Clark GJ, Ju X, Angel CE, et al. Human CD141+ (BDCA-3)+ dendritic cells (DCs) represent a unique myeloid DC subset that cross-presents necrotic cell antigens. J Exp Med. (2010) 207:1247-60. doi: 10.1084/jem.20092140

129. Sallusto F, Lanzavecchia A. Efficient presentation of soluble antigen by cultured human dendritic cells is maintained by granulocyte/macrophage colony-stimulating factor plus interleukin 4 and downregulated by tumor necrosis factor alpha. J Exp Med. (1994) 179:1109-18.

130. Romani N, Gruner S, Brang D, Kämpgen E, Lenz A, Trockenbacher B, et al. Proliferating dendritic cell progenitors in human blood. J Exp Med. (1994) 180:83-93.

131. Helft J, Böttcher J, Chakravarty P, Zelenay S, Huotari J, Schraml BU, et al. GM-CSF mouse bone marrow cultures comprise a heterogeneous population

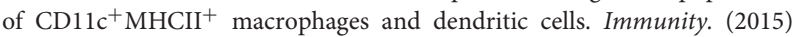
42:1197-211. doi: 10.1016/j.immuni.2015.05.018

132. Giusti P, Urban BC, Frascaroli G, Albrecht L, Tinti A, Troye-Blomberg M, et al. Plasmodium falciparum-infected erythrocytes and beta-hematin induce partial maturation of human dendritic cells and increase their migratory ability in response to lymphoid chemokines. Infect Immun. (2011) 79:272736. doi: 10.1128/IAI.00649-10

133. Boura M, Frita R, Góis A, Carvalho T, Hänscheid T. The hemozoin conundrum: is malaria pigment immune-activating, inhibiting, or simply a bystander? Trends Parasitol. (2013) 29:469-76. doi: 10.1016/j.pt.2013. 07.005

134. Coban C, Ishii KJ, Sullivan DJ, Kumar N. Purified malaria pigment (Hemozoin) enhances dendritic cell maturation and modulates the isotype of antibodies induced by a DNA vaccine. Infect Immun. (2002) 70:3939-43. doi: 10.1128/IAI.70.7.3939-3943.2002

135. Skorokhod OA, Alessio M, Mordmüller B, Arese P, Schwarzer E. Hemozoin (malarial pigment) inhibits differentiation and maturation of human monocyte-derived dendritic cells: a peroxisome proliferatoractivated receptor-gamma-mediated effect. J Immunol. (2004) 173:4066-74. doi: 10.4049/jimmunol.173.6.4066

136. Parroche P, Lauw FN, Goutagny N, Latz E, Monks BG, Visintin A, et al. Malaria hemozoin is immunologically inert but radically enhances innate responses by presenting malaria DNA to Toll-like receptor 9. Proc Natl Acad Sci USA. (2007) 104:1919-24. doi: 10.1073/pnas.0608745104

137. Brasel K, Smedt T De, Smith JL, Maliszewski CR. Generation of murine dendritic cells from flt3-ligand-supplemented bone marrow cultures. Blood. (2000) 96:3029-39. Available online at: http://www.bloodjournal.org/ content/96/9/3029

138. van de Hoef DL, Coppens I, Holowka T, Ben Mamoun C, Branch $\mathrm{O}$, Rodriguez A. Plasmodium falciparum-derived uric acid precipitates induce maturation of dendritic cells. PLoS ONE. (2013) 8:e55584. doi: 10.1371/journal.pone.0055584 
139. Gallego-Delgado J, Ty M, Orengo JM, van de Hoef D, Rodriguez A. A Surprising role for uric acid: the inflammatory malaria response. Curr Rheumatol Rep. (2014) 16:401. doi: 10.1007/s11926-013-0401-8

140. Hochrein H, O'Keeffe M. Dendritic cell subsets and toll-like receptors. In: Bauer S, Hartmann G, editors. Handbook of Experimental Pharmacology. Berlin; Heidelberg: Springer (2008). p. 153-79. doi: 10.1007/978-3-540-72167-3

141. Gallego-Marin C, Schrum JE, Andrade WA, Shaffer SA, Giraldo LF, Lasso AM, et al. Cyclic GMP-AMP synthase is the cytosolic sensor of Plasmodium falciparum genomic DNA and activates type I IFN in malaria. J Immunol. (2017) 200:768-74. doi: 10.4049/jimmunol.1701048

142. Sisquella X, Ofir-Birin Y, Pimentel MA, Cheng L, Abou Karam P, Sampaio NG, et al. Malaria parasite DNA-harbouring vesicles activate cytosolic immune sensors. Nat Commun. (2017) 8:1985. doi: 10.1038/s41467-017-02083-1

143. Nwakanma DC, Gomez-Escobar N, Walther M, Crozier S, Dubovsky F, Malkin E, et al. Quantitative detection of Plasmodium falciparum DNA in saliva, blood, and urine. J Infect Dis. (2009) 199:1567-74. doi: 10.1086/598856

144. Krishnegowda G, Hajjar AM, Zhu J, Douglass EJ, Uematsu S, Akira S, et al. Induction of proinflammatory responses in macrophages by the glycosylphosphatidylinositols of Plasmodium falciparum: cell signaling receptors, glycosylphosphatidylinositol (GPI) structural requirement, and regulation of GPI activity. J Biol Chem. (2005) 280:8606-16. doi: 10.1074/jbc.M413541200

145. Baccarella A, Fontana MF, Chen EC, Kim CC. Toll-like receptor 7 mediates early innate immune responses to malaria. Infect Immun. (2013) 81:4431-42. doi: 10.1128/IAI.00923-13

146. Campos FM, Franklin BS, Teixeira-Carvalho A, Filho AL, de Paula SC, Fontes CJ, et al. Augmented plasma microparticles during acute Plasmodium vivax infection. Malar J. (2010) 9:327. doi: 10.1186/1475-2875-9-327

147. Nantakomol D, Dondorp AM, Krudsood S, Udomsangpetch R, Pattanapanyasat K, Combes V, et al. Circulating red cell-derived microparticles in human malaria. J Infect Dis. (2011) 203:700-6. doi: 10.1093/infdis/jiq104

148. Couper KN, Barnes T, Hafalla JCR, Combes V, Ryffel B, Secher T, et al. Parasite-derived plasma microparticles contribute significantly to malaria infection-induced inflammation through potent macrophage stimulation. PLoS Pathog. (2010) 6:e1000744. doi: 10.1371/journal.ppat.1000744

149. Mantel PY, Hoang AN, Goldowitz I, Potashnikova D, Hamza B, Vorobjev I, et al. Malaria-infected erythrocyte-derived microvesicles mediate cellular communication within the parasite population and with the host immune system. Cell Host Microbe. (2013) 13:521-34. doi: 10.1016/j.chom.2013. 04.009

150. Laurens MB, Thera MA, Coulibaly D, Ouattara A, Kone AK, Guindo $\mathrm{AB}$, et al. Extended safety, immunogenicity and efficacy of a bloodstage malaria vaccine in Malian children: 24-month follow-up of a randomized, double-blinded phase 2 trial. PLoS ONE. (2013) 8:e79323. doi: 10.1371/journal.pone.0079323

151. Wilson NO, Jain V, Roberts CE, Lucchi N, Joel PK, Singh MP, et al. CXCL4 and CXCL10 predict risk of fatal cerebral malaria. Dis Markers. (2011) 30:39-49. doi: 10.3233/DMA-2011-0763

152. Jain V, Singh PP, Silawat N, Patel R, Saxena A, Bharti PK, et al. A preliminary study on pro- and anti-inflammatory cytokine profiles in Plasmodium vivax malaria patients from central zone of India. Acta Trop. (2010) 113:263-8. doi: 10.1016/j.actatropica.2009.11.009

153. Herbert F, Tchitchek N, Bansal D, Jacques J, Pathak S, Bécavin C, et al. Evidence of IL-17, IP-10, and IL-10 involvement in multipleorgan dysfunction and IL-17 pathway in acute renal failure associated to Plasmodium falciparum malaria. J Transl Med. (2015) 13:369. doi: 10.1186/s12967-015-0731-6

154. Kempaiah P, Anyona SB, Raballah E, Davenport GC, Were T, Hittner JB, et al. Reduced interferon (IFN)- $\alpha$ conditioned by IFNA2 $(-173)$ and IFNA8 (-884) haplotypes is associated with enhanced susceptibility to severe malarial anemia and longitudinal all-cause mortality. Hum Genet. (2012) 131:1375-91. doi: 10.1007/s00439-012-1175-1

155. Montes de Oca M, Kumar R, Rivera F de L, Amante FH, Sheel M, Faleiro $\mathrm{RJ}$, et al. Type I interferons regulate immune responses in humans with blood-stage Plasmodium falciparum infection. Cell Rep. (2016) 17:399-412. doi: 10.1016/j.celrep.2016.09.015

156. Wykes MN, Kay JG, Manderson A, Liu XQ, Brown DL, Richard DJ, et al. Rodent blood-stage Plasmodium survive in dendritic cells that infect naive mice. Proc Natl Acad Sci USA. (2011) 108:11205-10. doi: 10.1073/pnas. 1108579108

157. Vuckovic S, Abdul Wahid FS, Rice A, Kato M, Khalil D, Rodwell R, et al. Compartmentalization of allogeneic T-cell responses in the bone marrow and spleen of humanized NOD/SCID mice containing activated human resident myeloid dendritic cells. Exp Hematol. (2008) 36:1502-12. doi: 10.1016/j.exphem.2008.06.011

158. Minkah NK, Schafer C, Kappe SHI. Humanized mouse models for the study of human malaria parasite biology, pathogenesis, and immunity. Front Immunol. (2018) 9:807. doi: 10.3389/fimmu.2018.00807

159. Broutier L, Mastrogiovanni G, Verstegen MM, Francies HE, Gavarró LM, Bradshaw CR, et al. Human primary liver cancer-derived organoid cultures for disease modeling and drug screening. Nat Med. (2017) 23:1424-35. doi: $10.1038 / \mathrm{nm} .4438$

160. Spence JR, Mayhew CN, Rankin SA, Kuhar MF, Vallance JE, Tolle K, et al. Directed differentiation of human pluripotent stem cells into intestinal tissue in vitro. Nature. (2011) 470:105-9. doi: 10.1038/nature09691

161. Heo I, Dutta D, Schaefer DA, Iakobachvili N, Artegiani B, Sachs N, et al. Modelling Cryptosporidium infection in human small intestinal and lung organoids. Nat Microbiol. (2018) 3:814-23. doi: 10.1038/s41564-018-0177-8

162. Klotz C, Aebischer T, Seeber F. Stem cell-derived cell cultures and organoids for protozoan parasite propagation and studying host-parasite interaction. Int J Med Microbiol. (2012) 302:203-9. doi: 10.1016/j.ijmm.2012.07.010

Conflict of Interest Statement: The authors declare that the research was conducted in the absence of any commercial or financial relationships that could be construed as a potential conflict of interest.

Copyright (c) 2019 Yap, Lundie, Beeson and O'Keeffe. This is an open-access article distributed under the terms of the Creative Commons Attribution License (CC BY). The use, distribution or reproduction in other forums is permitted, provided the original author(s) and the copyright owner(s) are credited and that the original publication in this journal is cited, in accordance with accepted academic practice. No use, distribution or reproduction is permitted which does not comply with these terms. 